Article

\title{
Lipophilicity of Bacteriochlorin-Based Photosensitizers as a Determinant for PDT Optimization through the Modulation of the Inflammatory Mediators
}

\author{
Barbara Pucelik ${ }^{1,2}$, Luis G. Arnaut ${ }^{3}$ (D) and Janusz M. Dąbrowski 1,*(D) \\ 1 Faculty of Chemistry, Jagiellonian University, 30-387 Kraków, Poland; barbara.pucelik@gmail.com \\ 2 Malopolska Centre of Biotechnology, Jagiellonian University, 30-387 Kraków, Poland \\ 3 CQC, Department of Chemistry, University of Coimbra, 3004-535 Coimbra, Portugal; lgarnaut@ci.uc.pt \\ * Correspondence: jdabrows@chemia.uj.edu.pl; Tel.: +48-12-686-2488; Fax: +48-12-686-2750
}

Received: 2 November 2019; Accepted: 18 December 2019; Published: 19 December 2019

\begin{abstract}
Photodynamic therapy (PDT) augments the host antitumor immune response, but the role of the PDT effect on the tumor microenvironment in dependence on the type of photosensitizer and/or therapeutic protocols has not been clearly elucidated. We employed three bacteriochlorins $\left(\mathrm{F}_{2} \mathrm{BOH}\right.$, $\mathrm{F}_{2} \mathrm{BMet}$ and $\mathrm{Cl}_{2} \mathrm{BHep}$ ) of different polarity that absorb near-infrared light (NIR) and generated a large amount of reactive oxygen species (ROS) to compare the PDT efficacy after various drug-to-light intervals: $15 \mathrm{~min}$. (V-PDT), 3h (E-PDT) and 72h (C-PDT). We also performed the analysis of the molecular mechanisms of PDT crucial for the generation of the long-lasting antitumor immune response. PDT-induced damage affected the integrity of the host tissue and developed acute (protocol-dependent) local inflammation, which in turn led to the infiltration of neutrophils and macrophages. In order to further confirm this hypothesis, a number of proteins in the plasma of PDT-treated mice were identified. Among a wide range of cytokines (IL-6, IL-10, IL-13, IL-15, TNF- $\alpha$, GM-CSF), chemokines (KC, MCP-1, MIP1 $\alpha$, MIP1 $\beta$, MIP2) and growth factors (VEGF) released after PDT, an important role was assigned to IL-6. PDT protocols optimized for studied bacteriochlorins led to a significant increase in the survival rate of BALB/c mice bearing CT26 tumors, but each photosensitizer (PS) was more or less potent, depending on the applied DLI (15 $\mathrm{min}, 3 \mathrm{~h}$ or $72 \mathrm{~h}$ ). Hydrophilic $\left(\mathrm{F}_{2} \mathrm{BOH}\right)$ and amphiphilic $\left(\mathrm{F}_{2} \mathrm{BMet}\right) \mathrm{PSs}$ were equally effective in V-PDT ( $>80$ cure rate). $\mathrm{F}_{2}$ BMet was the most efficient in E-PDT (DLI $=3 \mathrm{~h}$ ), leading to a cure of $65 \%$ of the animals. Finally, the most powerful PS in the C-PDT (DLI $=72 \mathrm{~h}$ ) regimen turned out to be the most hydrophobic compound $\left(\mathrm{Cl}_{2} \mathrm{BHep}\right)$, allowing $100 \%$ of treated animals to be cured at a light dose of only $45 \mathrm{~J} / \mathrm{cm}^{2}$.
\end{abstract}

Keywords: bacteriochlorins; chemokines; cytokines; photodynamic therapy; immune response

\section{Introduction}

Photodynamic therapy (PDT) is a promising therapeutic approach to cancer, which in recent years entered the mainstream therapeutic options in oncology [1-3]. PDT aims at the destruction of the primary tumor without damaging surrounding, healthy tissues, and at the stimulation of anti-tumor immunity. There are three main mechanisms of PDT: the direct killing of cancer cells by photogenerated reactive oxygen species (ROS), tumor-associated vascular damage and activation of anti-tumor immune responses [2,4]. These mechanisms suggest that intricate relations between the nature of the photosensitizer (PS), PS dose, light dose, drug-to-light interval (DLI), the oxygen concentration in the targeted tissue and the mechanism of cell death [2,5-7] are likely to affect the outcome of PDT efficacy. 
In practice, three fundamental PDT approaches are investigated: vascular-targeted PDT (V-PDT), tumor cellular-targeted PDT (C-PDT) and endothelial cells-targeted PDT (E-PDT). V-PDT is characterized by short drug-to-light intervals (DLI $=5-15 \mathrm{~min}$ ). The main target of this protocol is the tumor vascularization. C-PDT targets tumour cells directly through specific molecules on cancer cells surfaces. In this case, longer drug-to-light intervals (DLI $>12 \mathrm{~h}$ ) are used [8-11]. At intermediate DLIs (e.g., $3 \mathrm{~h}$ ) the PS is found mainly in the blood and endothelial cells, with partial accumulation in tumor cells [6,12], and protocols using such intermediate DLIs are designated here as E-PDT.

The first step in PDT is the selection of a PS with physicochemical and pharmacological properties adequate for the intended PDT regime [13]. The hydrophilicity/lipophilicity of the PS is one of the most important factors influencing its biological behavior, including uptake by cancer cells, intracellular localization, biodistribution and pharmacokinetics [14,15]. The high expression of low-density lipoprotein (LDL) receptors in tumors makes LDL-bounded lipophilic PSs more likely to achieve LDL-receptor-mediated endocytosis than hydrophilic drugs. These, in contrast, are mainly associated with serum proteins such as albumin and tend to localize in tumor vessels [16]. Many second-generation PSs were designed to be rather hydrophobic in order to increase their accumulation in tumors, and thus improve the outcome of C-PDT [17]. The challenge of aggregation of hydrophobic PS in biological fluids has been addressed using delivery vehicles such as liposomes, lipoproteins or micelles. Hydrophilic photosensitizers are much easier to prepare for in vivo administration, but they are less likely to permeate cancer cells and tend to show faster clearance from the organism. Nevertheless, their tendency to interact with plasma proteins following intravenous administration (i.v.) [18] can lead to significant vascular effects in V-PDT [19,20]. Amphiphilic compounds, which contain both hydrophilic and hydrophobic moieties in their molecular structure, are quite versatile and promising for clinical translation [21-23]. Their pharmacokinetics and biodistribution largely determine the choice of the optimal drug-to-light interval $[15,24]$, and the possibility to achieve PS accumulation in both individual cell organelles and intracellular spaces [25].

Photosensitizers bearing fluorine, chlorine or other halogen atoms usually display an enhanced photodynamic effect [26-28]. This is assigned to the so-called "heavy atom effect" resulting from the increased spin-orbit coupling originating from atoms with higher atomic numbers, and consequently, higher spin-orbit coupling constants $(\zeta=0.24$ for $\mathrm{H}, \zeta=269$ for $\mathrm{F}$ and $\zeta=586 \mathrm{for} \mathrm{Cl})$. Hence, the internal heavy atom effect accelerates the $\mathrm{S}_{1} \rightarrow \mathrm{T}_{1}$ intersystem-crossing rate, increases the triplet quantum yields $\left(\Phi_{\mathrm{T}}\right)$ of photosensitizers and consequently improves the ability to generate ROSs. In addition, the introduction of fluorine and chlorine atoms into the PS structure leads to a change in their polarity, which in turn can increase the rate of transport of biologically-active compounds through lipid membranes [29-34].

It is widely recognized that PDT regimes can trigger rapid inflammatory responses that are essential for the activation of antitumor immunity [35-37], improving long-term tumor control and offering protection against metastasis [38]. Unlike most chemotherapies, which mainly lead to apoptotic cell death, PDT may also lead to necrosis or immunogenic cell death (ICD), which can result in controlled inflammation, which in turn leads to further stimulation of the immune system [7,37,39-41]. The generation of the post-PDT antitumor response involves the participation of various mechanisms based on the secretion of cytokines and mediators associated with the inflammatory process, increased level of neutrophils in the blood combined with neutrophil recruitment to the treated areas, as well as induction of acute-phase proteins and activation of the complement system [7,35,40,42]. PDT-induced inflammation is associated with the influx of the cells of the immune system to the treated area, and these cells contribute to the development of an immune response that recognizes cells that survived the therapy or are found in other parts of the body in the form of metastases [21].

Changes in the peritumoral microenvironment induced by PDT seem to influence the activity of non-specific mechanisms of the innate immune system. The cells involved in non-specific mechanisms include phagocytic cells-macrophages, granulocytes, monocytes and several mediators (chemokines and cytokines) $[43,44]$. PDT-induced inflammation may also activate mechanisms of adaptive (or 
specific) immune response generated when antigens are recognized by the lymphocyte population, capable of inducing immunological memory and of causing the regression of distant established tumors that received no treatment [17]. Cells dying after PDT can be a source of antigens and stimulate cells of the immune system that infiltrate the tumor, eventually leading to anti-tumor immunity [45-47]. The development of effective, adaptive immune responses requires the prior engagement of innate immunity [39].

The main purpose of this work is to investigate PDT regimes with three bacteriochlorin-type photosensitizers of different polarity and to relate the outcomes of these regimes to the properties of the PSs, namely their physicochemical properties, subcellular localization, pharmacokinetics, ROS generation and immune response. This work offers a basis for the optimization of immune responses with PDT and the rational design of combinations between PDT and immunotherapies. The bacteriochlorins selected for this study are presented in Scheme 1. The synthesis and some photophysical properties of $\mathrm{F}_{2} \mathrm{BOH}, \mathrm{F}_{2} \mathrm{BMet}$ (named redaporfin) and $\mathrm{Cl}_{2} \mathrm{BHep}$ have been reported [21-23,48], as well as the pharmacokinetics and biodistribution of $\mathrm{F}_{2} \mathrm{BOH}$ and $\mathrm{F}_{2} \mathrm{BMet}[14,15,24]$. Although some in vitro studies and the PDT of tumor-bearing mice have been published for $\mathrm{F}_{2} \mathrm{BOH}$ and $\mathrm{F}_{2} \mathrm{BMet}$ [21-24], they were repeated and extended in this work to afford a more direct comparison with the corresponding studies with $\mathrm{Cl}_{2} \mathrm{BHep}$.

(a)

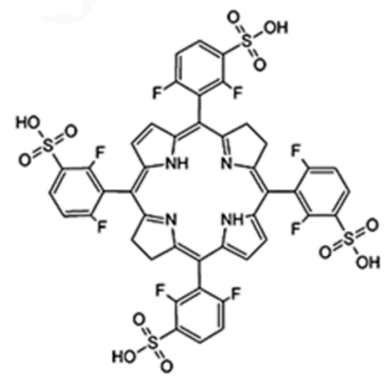

$\mathrm{F}_{2} \mathrm{BOH}$ (b)

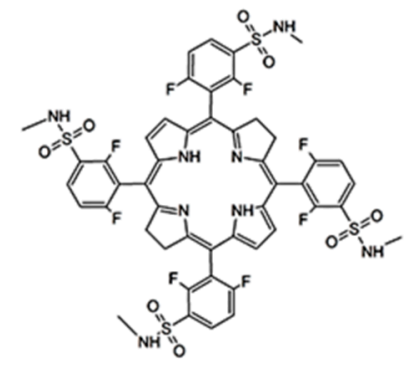

$\mathrm{F}_{2}$ BMet (c)

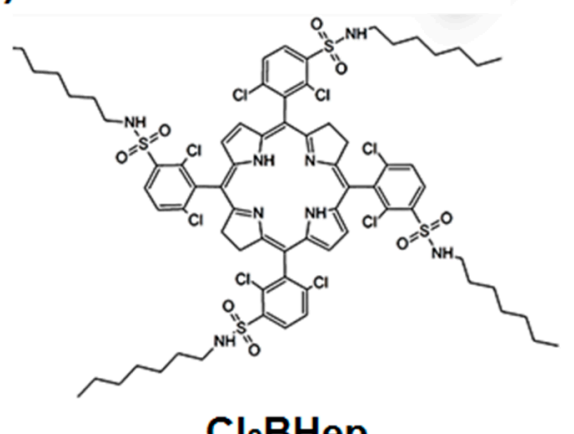

Scheme 1. Chemical structure of investigated halogenated bacteriochlorin derivatives.

\section{Experimental Section}

\subsection{Chemicals and Photosensitizers}

All commercial chemicals and reagents were of analytical grade and were purchased from Sigma-Aldrich. 5,10,15,20-tetrakis(2,6-difluoro-3-sulfophenyl)bacteriochlorin $\left(\mathrm{F}_{2} \mathrm{BOH}\right)$, 5,10,15,20-tetrakis(2,6-difluoro-3-N-methylsulfamoylphenyl)bacteriochlorin ( $\mathrm{F}_{2} \mathrm{BMet}$, redaporfin) and 5,10,15,20-tetrakis(2,6-dichloro-3-N-heptylsulfamoylphenyl)bacteriochlorin $\left(\mathrm{Cl}_{2} \mathrm{BHep}\right)$ were prepared according to reported procedures [21-23,48].

\subsection{Spectroscopic Studies}

Electronic absorption spectra were recorded in a Hewlett Packard HP8453 spectrophotometer. Solutions containing samples of photosensitizers were dissolved in the selected solvents in quartz cuvettes. Using measured absorbance for various concentrations of bacteriochlorins, either in dimethyl sulfoxide (DMSO) or in ethanol, the molar absorption coefficients were determined from Beer's law. Fluorescence emission spectra were recorded from $700 \mathrm{~nm}$ to $800 \mathrm{~nm}$ with excitation at $\lambda \approx$ $505 \mathrm{~nm}$. The excitation and emission slits were both set to $8 \mathrm{~nm}$ and scanning speed to $50 \mathrm{~nm} / \mathrm{min}$. Fluorescence spectra were recorded with a Perkin Elmer Fluorescence Spectrometer LS 55 (Perkin Elmer, Waltham, MA, USA). Fluorescence lifetimes were determined using a Time-Correlated Single Photon Counting (TCSPC) mode using the FluoroLog-3 Spectrophotometer (Horiba Jobin Yvon, Glasgow, UK). 
The instrument was equipped with $340 \mathrm{~nm}$ picoseconds-pulsed light-emitting diodes (LEDs) as the excitation source in the MCS mode. During measurements, the Instrument Response Function (IRF) was obtained from a non-fluorescence suspension of colloidal silica (LUDOX 30\%, Sigma Aldrich, Schnelldorf, Germany), held in a $10 \mathrm{~mm}$ path length quartz cell, and was considered to be wavelength independent. All lifetimes were fit to a $\chi^{2}$ value of less than 1.1, and with residuals trace symmetrically distributed around the zero axes. Fluorescence quantum yield for $\mathrm{F}_{2} \mathrm{BOH}$ and $\mathrm{Cl}_{2} \mathrm{BHep}$ in DMSO was determined using the comparative method according to the Equation (1):

$$
\Phi_{\mathrm{F}}=\Phi_{\mathrm{FStd}} \frac{F \cdot A_{S t d} \cdot n^{2}}{F_{S t d} \cdot A \cdot n_{S t d}^{2}},
$$

where $\mathrm{F}$ and $\mathrm{F}_{\mathrm{Std}}$ are the areas under the fluorescence emission curves of the sample and the standard, $A$ and $A_{S t d}$ are the absorbance of the sample and the standard, and $\eta / \eta S t d$ are the refractive indices of the solvent used for the sample and the standard, respectively. Redaporfin $\left(\Phi_{\mathrm{FStd}}=0.138\right)$ was employed as the standard. The absorbance of the solutions at the excitation wavelength was in the range of 0.02 .

\subsection{ROS Detection with Fluorescent Probes}

3'-p-(aminophenyl)fluorescein (APF) and 3'-p-(hydroxyphenyl)fluorescein (HPF) were used to detect hydroxyl radicals. Singlet Oxygen Sensor Greenß(SOSG) was applied as a probe for singlet oxygen. Dihydroethidinum (DHE) was used to identify the superoxide ion. All probes were employed for the detection of various ROSs after the illumination of the photosensitizer. PS solutions were diluted to a final concentration of $5 \mu \mathrm{M}$ per well. A tested fluorescent probe was added at a final concentration of $10 \mu \mathrm{M}$. PS solutions were irradiated for various time intervals with a red light from the LED-based device (735 $\pm 20 \mathrm{~nm}$ ). A microplate reader (Tecan, Infinite M200 Reader, Tecan, Männedorf, Switzerland) was used for the acquisition of fluorescence signal immediately before and after illumination. APF fluorescence emission at $515 \mathrm{~nm}$ was determined upon excitation at $490 \mathrm{~nm}$. For SOSG, the corresponding values were 525 and $505 \mathrm{~nm}$, and $480 \mathrm{~nm}$ and $580 \mathrm{~nm}$ for DHE.

\subsection{Photodecomposition Experiments}

The photostability of bacteriochlorins was investigated following the measurement of their optical absorption in $5 \mu \mathrm{M}$ solutions prepared in DMSO and diluted in phosphate-buffered saline (PBS) (the DMSO content did not exceed $0.5 \%$ ). Continuous irradiation of an aerated solution was carried out using a LED at $735 \pm 20 \mathrm{~nm}$. The reaction progress was monitored by electronic spectroscopy using a Hewlett Packard HP8453 spectrophotometer.

\section{5. $\log P$ Determination}

The n-octanol/PBS partition coefficients $(\log \mathrm{P})$ were determined following the shake-flask method. The photosensitizers were dissolved in the mixture of n-octanol previously saturated with a solution of PBS and the same volume of PBS saturated with n-octanol. After the addition of the samples of each bacteriochlorin, the solutions were mixed on a vortex device (horizontally) and then the phases were separated by centrifugation ( $15 \mathrm{~min}, 8000 \mathrm{rpm}, \mathrm{RT}$ ). Next, the PBS/n-octanol phase was taken and diluted to obtain $0.5 \%$ of $\mathrm{PBS} / \mathrm{n}$-octanol content in the final solution. This solution was left into the ultrasonic bath. The fluorescence of each solution was measured using a Fluorescence Spectrometer LS 55 (Perkin Elmer, Waltham, MA, USA) and compared with the calibration curve to obtain the concentration of the photosensitizer. Partition coefficients were calculated from the ratio $\mathrm{coct}_{\mathrm{oct}} / \mathrm{C}_{\mathrm{PBS}}$, where $c_{\mathrm{oct}}$ and $\mathrm{C}_{\mathrm{PBS}}$ are the concentrations of the porphyrin derivatives in the n-octanol and in the PBS. 


\subsection{In Vitro Studies}

\subsubsection{Photosensitizer Formulation}

For the biological studies, due to the reduced solubility of $\mathrm{Cl}_{2} \mathrm{BHep}$ in water, the Pluronic-based micelles were applied to deliver it either to cells in vitro or to tumors in vivo. The formulation was prepared by a thin-film hydration method. Dynamic Light Scattering (DLS) using a Malvern Zetaziser Nano ZS system was employed to measure the hydrodynamic diameters $\left(D_{H}\right)$, size distributions and zeta potentials $(\zeta)$ of polymeric micelles. $\mathrm{Cl}_{2} \mathrm{BHep}$ concentrations in the formulations were determined and controlled by UV-vis spectrophotometry. Results are reported as the mean of three independent measurements with three different samples $(n=3)$. The weight percentage of Pluronic-based formulations was determined spectrophotometrically using the absorption calibration curves generated from the $\mathrm{Cl}_{2} \mathrm{BHep}$ standard solutions at known concentrations, as well as DLS measurements. Drug loading content (DL) and drug encapsulating efficiency (EE) were calculated based on the Equations (2) and (3) below [12]:

$$
\begin{aligned}
& D L(\%)=\frac{\text { weight of PS in micelles }}{\text { weight of micelles }} \cdot 100 \% \\
& E E(\%)=\frac{\text { weight of PS in micelles }}{\text { weight of the feeding PS }} \cdot 100 \%
\end{aligned}
$$

Electronic absorption spectra were recorded by HP8453 spectrophotometer using a $1 \mathrm{~cm}$ path-length quartz cell.

\subsubsection{Cell Cultures}

Murine colon carcinoma (CT26) cells were grown in full-strength Dulbecco's modified Eagle's medium (DMEM) with $4.5 \mathrm{~g} / \mathrm{L}$ glucose, L-glutamine, sodium pyruvate and $3.7 \mathrm{~g} / \mathrm{L} \mathrm{NaHCO}$ (BioTech) with the addition of $10 \%$ fetal bovine serum (FBS, PAN-Biotech, Aidenbach, Germany) and supplemented by antibiotics (penicillin/streptomycin, PAN-Biotech, Aidenbach, Germany). The cells were cultured in incubators maintained at $37{ }^{\circ} \mathrm{C}$ with $5 \% \mathrm{CO}_{2}$ under fully humidified conditions. All experiments were performed on cells in the logarithmic phase of growth. Media were replaced every two days and cells were subcultured using $0.25 \%$ trypsin-ethylenediaminetetraacetic acid (EDTA).

\subsubsection{Cellular Uptake}

CT26 cells were seeded on 96-plate microplate ( $10^{4}$ per well). After $24 \mathrm{~h}$, the cells were incubated with various PS concentrations for time intervals from $2 \mathrm{~h}$ up to $24 \mathrm{~h}$. Bacteriochlorin solutions were prepared by diluting stock solutions in DMSO or in micellar formulations (for $\mathrm{Cl}_{2} \mathrm{BHep}$ ) with the culture medium to the desired final concentration $(5 \mu \mathrm{M})$. The highest concentration of DMSO in the medium did not exceed $0.5 \%$. After incubation, the cells were washed twice with PBS and solubilized in $30 \mu \mathrm{L}$ of Triton X-100 and $70 \mu \mathrm{L}$ of DMSO/ethanol solution (1:3). The retention of cell-associated PSs was detected by fluorescence $\left(\lambda_{\mathrm{exc}}=505, \lambda_{\mathrm{em}}=750 \mathrm{~nm}\right.$ ) with the microplate reader (Tecan Infinite M200 Reader, Tecan, Männedorf, Switzerland).

\subsubsection{Cytotoxicity and Cell Survival Assay}

The MTT (3-(4,5dimethylthiazol-2-yl)2,5-diphenyl tetrazolium bromide) assay was used to quantify cell survival and PS-mediated cytotoxicity. After the cells were attached to the microplates, PS solutations at concentrations of 0 to $100 \mu \mathrm{M}$ were added to the cell medium. Cells were incubated for the appropriate time in the dark. Next, the PS solution of each well was removed, cells were washed in PBS and fresh culture medium supplemented with FBS and antibiotics was added to each well, and cells were returned to the incubator for $24 \mathrm{~h}$. MTT dissolved in PBS at content $10 \%$ of final solution was added to each well, and the microplates were further incubated for ca. $3 \mathrm{~h}$. Then, the medium was 
discarded, and $100 \mu \mathrm{L}$ of the mixture of DMSO:methanol (1:1) were added to the cultures and mixed thoroughly to dissolve the dark blue crystals of formazan.

Formazan quantification was performed using an automatic microplate reader (Tecan Infinite M200 Reader) by absorbance measurements at a $565 \mathrm{~nm}$. Each essay was replicated in at least three independent experiments.

\subsubsection{Photodynamic Effect}

On the basis of the cytotoxicity results, a nontoxic concentration of bacteriochlorin $(5 \mu \mathrm{M})$ was selected. Cells were incubated for the optimal time determined experimentally in the dark with each bacteriochlorin solution in the culture medium. After this incubation time, the cells were washed with PBS and irradiated with a $735 \pm 20 \mathrm{~nm}$ LED irradiation system. An LED illuminator (Photon Institute, Kraków, Poland) and sample chamber with stabilized temperature and the display was employed for illumination of the plate with seeded cells. The diode $(735 \mathrm{~nm} \pm 20 \mathrm{~nm})$ was adjusted to give a uniform spot of irradiated area with a fluence rate of $1.072 \mathrm{~mW}$ as measured with a power meter (Light Engine UNO 50, Tampa, FL, USA), and to excite the same number of molecules. Next, the cells were washed with fresh medium and the plates were returned to the incubator for $24 \mathrm{~h}$. Cell viability was determined by MTT assay in independent experiments performed $24 \mathrm{~h}$ post-irradiation. Each essay was replicated at least in three independent experiments.

\subsubsection{Intracellular Localization-CLSM Imaging}

The intracellular accumulation of bacteriochlorins was assessed in CT26 cancer cells. Prior to imaging, CT26 cells were seeded on microscopic slides at a density of $1 \cdot 10^{5}$ cells, and were kept at $37^{\circ} \mathrm{C}$ in a $95 \%$ air- and $5 \% \mathrm{CO}_{2}$-humidified atmosphere, for $24 \mathrm{~h}$. After being washed with fresh medium, the cells were incubated in the dark with $10 \mu \mathrm{M}$ solution of each bacteriochlorin-prepared cell medium, for $24 \mathrm{~h}$. Next, after being washed with Hank's Balanced Salt Solution (HBSS, composition: $0.14 \mathrm{M} \mathrm{NaCl}, 0.005 \mathrm{M} \mathrm{KCl}, 0.001 \mathrm{M} \mathrm{CaCl}_{2}, 0.0004 \mathrm{M} \mathrm{MgSO}_{4} \cdot 7 \mathrm{H}_{2} \mathrm{O}, 0.0005 \mathrm{M} \mathrm{MgCl}_{2} \cdot 6 \mathrm{H}_{2} \mathrm{O}, 0.0003 \mathrm{M}$ $\mathrm{Na}_{2} \mathrm{HPO}_{4} \cdot 2 \mathrm{H}_{2} \mathrm{O}, 0.0004 \mathrm{M} \mathrm{KH}_{2} \mathrm{PO}_{4}, 0.006 \mathrm{M}$ D-glucose, $0.004 \mathrm{M} \mathrm{NaHCO}_{3}$ ), the cells were incubated with specific intracellular organelle probes: $100 \mathrm{nM}$ Mito-Tracker green, $1 \mu \mathrm{M}$ ER-Tracker green, $1 \mu \mathrm{M}$ Lyso-Tracker red (Molecular Probes, Invitrogen Life Technologies, CA, USA), diluted in HBSS buffer. In addition, cells were incubated for $10 \mathrm{~min}$ with Hoechst 33342 . After $30 \mathrm{~min}$ incubation, at $37^{\circ} \mathrm{C}$, in the dark, the cells were washed with HBSS two times, and the slide was transferred to the microscope stage, and cells were visualized under a confocal microscope Zeiss LSM 880 (Carl Zeiss, Jena, Germany) with a $40 \times$ oil immersion objective. Images were analyzed by Zeiss ZEN Software.

\subsection{In Vivo Studies}

\subsubsection{Tissue Distribution and Pharmacokinetics of $\mathrm{Cl}_{2} \mathrm{BHep}$ in BALB/c mice}

All experiments were carried out with approval no. 42/2014 and 190/2018 of the First Ethics Committee for Research on Animals, Kraków, Poland. BALB/c (8-9-weeks-old males, Animal Facility, FBBiB JU) were used to perform in vivo studies. The animals were humanely treated and supplied with food and water ad libitum. The CT26 cells $\left(0.5 \times 10^{6}\right.$ in PBS suspension) were implanted subcutaneously into the right thigh of male BALB/c mice. The intravenous administration of the drug formulation was done when the tumor attained a diameter of 5-6 $\mathrm{mm}$ in each animal, which usually took about seven days after inoculation. Each formulation, corresponding to $1.5 \mathrm{mg} \cdot \mathrm{kg}^{-1} \mathrm{of}^{\mathrm{Cl}_{2} \mathrm{BHep}}$ was injected into the tail vein of each animal, and tissue distribution was evaluated at $15 \mathrm{~min}, 3 \mathrm{~h}$ and $72 \mathrm{~h}$ after administration. At the selected time points post-injection, the mice were anesthetized with ketamine and xylazine and sacrificed. For each animal, selected organs and tissue samples were collected separately and weighed. To extract the pigments, we separately homogenized tissue samples in EtOH/DMSO solution (75:25) over 1 min using a Yellowline by an IKA DI 25 basic animal tissue homogenizer. The homogenate was centrifuged, the supernatant was collected, and the pellet was 
re-extracted four more times using the procedure described above to ensure complete recovery of the drug. The extracts were pooled and the fluorescence analysis of the extracts was done. The samples were excited at $505 \mathrm{~nm}$, and the fluorescence spectra were recorded in a range of $600-800 \mathrm{~nm}$. The amount of $\mathrm{Cl}_{2} \mathrm{BHep}$ in the tissues was reported as the average from four animals (with the standard error of the mean (SEM)). The concentration of $\mathrm{Cl}_{2} \mathrm{BHep}$ was estimated from the fluorescence intensity of this bacteriochlorin in samples with known concentrations.

\subsubsection{In Vivo Photodynamic Therapy with Bacteriochlorins}

The antitumor efficacy of the bacteriochlorins was evaluated in BALB/c mice bearing CT26 tumors. When the tumor volume reached about $4-5 \mathrm{~cm}$ in diameter, these mice were randomly assigned to experimental groups $(n=6)$. For safe PS administration, due to the lipophilic character of each compound, the $\mathrm{F}_{2} \mathrm{BOH}$ was prepared in saline solution, $\mathrm{F}_{2}$ BMet was formulated in $\mathrm{CrEL} / \mathrm{EtOH} / \mathrm{NaCl}$ $0.9 \%(0.2: 1: 98.8, v: v: v)^{22}$, and $\mathrm{Cl}_{2} \mathrm{BHep}$ was encapsulated in Pluronic P123 $(10 \% w / v)$ micelles ${ }^{12}$. Each bacteriochlorin was administered via the tail vein injection with a dosage of $1.5 \mathrm{mg} \mathrm{kg}^{-1} \mathrm{BW}$. The tumor irradiation was performed at DLI $=15 \mathrm{~min}, \mathrm{DLI}=3 \mathrm{~h}$ or DLI $=72 \mathrm{~h}$ using a laser (Omicron laser model LDM750.300.CWA.L.M equipped with optical fiber model FD/Medlight, Ecublens, Switzerland) at $750 \mathrm{~nm}$, radiant exposures ranging $45-105 \mathrm{~J} \mathrm{~cm}^{-2}$ and a laser power of $130 \mathrm{~mW}$. The illuminated area with a diameter of $1.3 \mathrm{~cm}$ was kept constant during irradiation. Survival curves were estimated by means of the Kaplan-Meier analysis.

\subsubsection{Analysis of Serum Inflammatory Cytokines with MAGPIX System}

To determine the concentration of a panel of inflammatory cytokines (IL-6, IL-10, IL-13, IL-15, KC, MIP-2, LIX, LIF, MCP-1, MIP- $1 \alpha$, MIP-1 $\beta$, IP-10, MIG, GM-CSF, TNF $\alpha$ and VEGF) listed in Table 1, in the mice sera $(n=6-7)$ before and after treatment, the MAGPIX system was employed. The test was replicated three times.

Table 1. Inflammatory cytokines/chemokines analyzed in this work.

\begin{tabular}{lc}
\hline \multicolumn{1}{c}{ Cytokine/Chemokine } & Abbreviation \\
\hline Interleukin 6 & IL-6 \\
Interleukin 10 & IL-10 \\
Interleukin 13 & IL-13 \\
Interleukin 15 & IL-15 \\
Keratinocyte-derived chemokine/C-X-C motif chemokine receptor 1 (CXCL1) & KC \\
Macrophage inflammatory protein 2 (MIP-2)/C-X-C motif chemokine ligand 2 (CXCL2) & MIP-2 \\
The murine homolog of ENA-78/C-X-C motif chemokine ligand 5 (CXCL5) & LIX \\
Leukemia inhibitory factor (interleukin 6 class cytokine) & LIF \\
Monocyte chemoattractant protein-1 & MCP-1 \\
Macrophage inflammatory protein 1 alpha & MIP-1 $\alpha$ \\
Macrophage inflammatory protein 1 beta & MIP-1 $\beta$ \\
Interferon gamma-induced protein 10/C-X-C motif chemokine 10 (CXCL10) & IP-10 \\
Monokine induced by interferon-gamma/C-X-C motif chemokine ligand 9 (CXCL9) & MIG \\
Granulocyte-macrophage colony-stimulating factor & GM-CSF \\
Tumor necrosis factor-alpha & TNF $\alpha$ \\
Vascular endothelial growth factor & VEGF \\
\hline
\end{tabular}

The analysis was performed using the MCYTOMAG-70K 16-Plex Panel (MerckMillopore, Burlington, MA, USA) according to the manufacturer's instructions. In total, samples from healthy and tumor-bearing mice, as well as before and after treatment, were tested (Scheme 2). The results were analyzed with the MAGPIX xPONENT software (Burlington, MA, USA). 


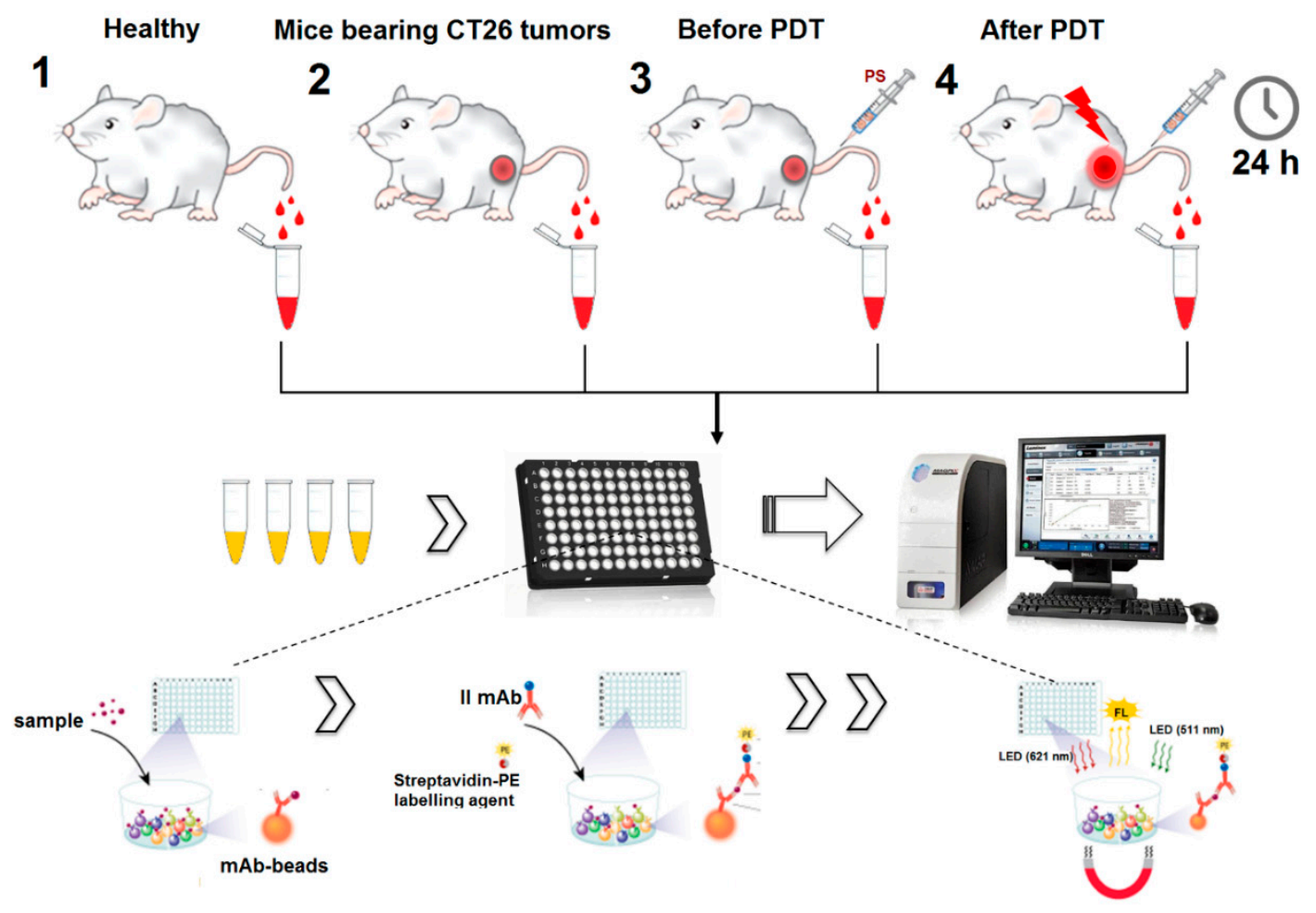

Scheme 2. Scheme for carrying out immunological analyses using the MAGPIX system.

\subsection{Statistical Analysis}

In both physicochemical and photochemical studies, as well as in vitro biological activity evaluation, the results are expressed as an average \pm the standard error of the mean (SEM). The sample size in biological tests in vitro was $n=6-12$ in each experimental group. All experiments were repeated independently at least three times. The Student's t-test or Welch's Mann-Whitney U-test (Luminex analysis) was used for the determination of statistical significance. Results were considered as statistically significant with a confidence level of $95 \%(p<0.05)$. Statistical analysis was performed with the STATISTICA 12.5 (StatSoft, Kraków, Poland).

\section{Results}

\subsection{Photosensitizers}

The synthesis and characterization of $\mathrm{F}_{2} \mathrm{BOH}, \mathrm{F}_{2} \mathrm{BMet}$ and $\mathrm{Cl}_{2} \mathrm{BHep}$ from their halogenated 5,10,15,20-tetraphenylporphyrin precursors were recently described elsewhere [23,27,48].

\subsection{Spectroscopic Characterization of Photosensitizers}

All investigated photosensitizers exhibit the characteristic bacteriochlorin absorption spectrum with a broad near-UV Soret, a narrow band in the green $(\approx 510 \mathrm{~nm})$ and a near-infrared $Q_{y}$ band $(\approx$ $745 \mathrm{~nm}$ ) of high intensity that is crucial for PDT. Representative absorption and fluorescence spectra recorded in DMSO are shown in Figure 1. Table 2 summarizes the important photophysical properties of these photosensitizers. The high molar absorption coefficients of these photosensitizers enable their use at much lower concentrations than their porphyrin and chlorin analogs [5]. Moreover, their absorption of NIR light allows for the use of light that penetrates more deeply into human tissues than red light. 


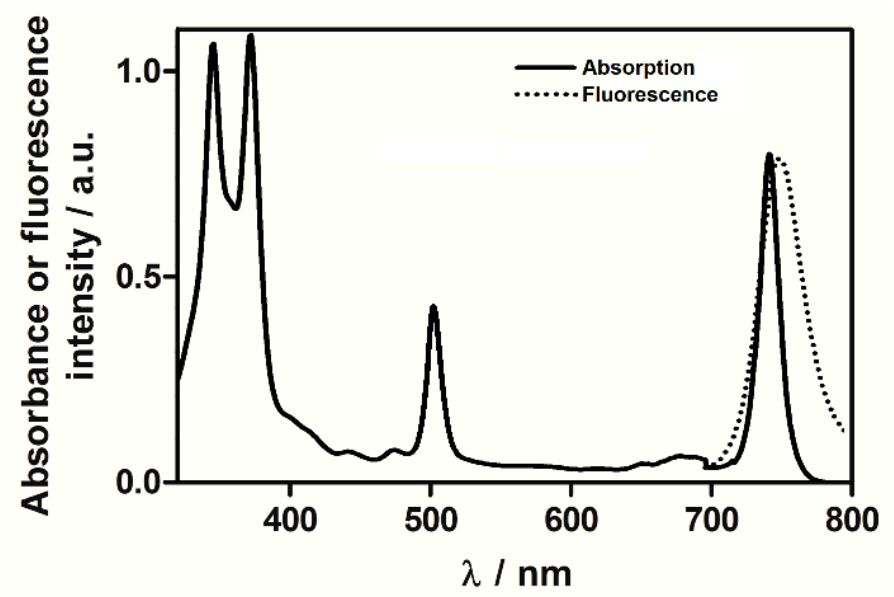

Figure 1. Representative, normalized absorption and fluorescence spectra of $\mathrm{F}_{2} \mathrm{BMet}$ in dimethyl sulfoxide (DMSO).

Table 2. Photophysical properties of investigated bacteriochlorins determined in ethanol (EtOH) and their lipophilicity $(\log P)$.

\begin{tabular}{|c|c|c|c|c|c|c|c|c|}
\hline PS & 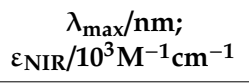 & $\lambda_{\mathrm{ff}} / \mathrm{nm}$ & $\Phi_{\mathrm{F}}$ & $\tau_{\mathrm{F}} / \mathbf{n s}$ & $\Phi_{\mathrm{pb}} / 10^{-6}$ & $\Phi_{\Delta}$ & $\tau_{\mathrm{T}} / \mathbf{n s}$ & $\log P$ \\
\hline $\mathrm{F}_{2} \mathrm{BOH}$ & $743 ; 70.0[24]$ & 764 & 0.023 & 3.90 & $1620^{a}$ & 0.44 [49] & $268[23]$ & -1.4 \\
\hline $\mathrm{F}_{2} \mathrm{BMet}$ & $743 ; 100[23]$ & 768 & 0.138 & 3.91 & $75^{\mathrm{a}}$ & $0.43[49]$ & $216[23]$ & 1.9 \\
\hline $\mathrm{Cl}_{2} \mathrm{BHep}$ & $746 ; 76.0[49]$ & 752 & 0.008 & 1.05 & $55^{\mathrm{a}}$ & $0.63[23]$ & 295 [49] & 4.5 \\
\hline
\end{tabular}

The fluorescence lifetimes of $\mathrm{F}_{2} \mathrm{BOH}$ and $\mathrm{F}_{2} \mathrm{BMet}$ are comparable. This is due to their structural similarity and the presence of eight fluorine atoms in the phenyl rings located in the meso positions of the tetrapyrrole macrocycle. $\mathrm{Cl}_{2} \mathrm{BHep}$ is characterized by a much shorter fluorescence lifetime, as expected from the presence of eight chlorine atoms and their higher spin-orbital coupling constants $(\zeta)$ than fluorine atoms. The difference in fluorescence quantum yields can be assigned to the same effect. $\mathrm{Cl}_{2} \mathrm{BHep}$ indicates the lowest $\Phi_{\mathrm{F}}$ value among other tested compounds $\left(\Phi_{\mathrm{F}}=0.008\right)$. The relatively high value of $\Phi_{\mathrm{F}}$ determined for $\mathrm{F}_{2}$ MBet suggests the use of this PS in photodiagnosis.

\subsection{ROS Detection by Fluorescent Probes}

The ability of bacteriochlorins to produce different ROSs after illumination was monitored using APF, HPF, DHE and SOSG fluorescent probes. Figure 2 shows that all investigated bacteriochlorins activate probes specific for singlet oxygen as well as for oxygen-centered radicals. $\mathrm{F}_{2} \mathrm{BOH}$ and $\mathrm{F}_{2} \mathrm{BMet}$ tend to give lower SOSG fluorescence intensities than $\mathrm{Cl}_{2} \mathrm{BHep}$ (Figure 2d), which is consistent with the higher singlet oxygen quantum yield of $\mathrm{Cl}_{2} \mathrm{BHep}$ presented in Table 2. $\mathrm{Cl}_{2} \mathrm{BHep}$ also tends to give higher APF and HPF fluorescences than other bacteriochlorins, suggesting that this derivative is the most effective in producing oxygen-centered radicals (Figure 2a,b). This is consistent with determinations of the triplet quantum yields of chlorinated and fluorinated tetraphenyl-bacteriochlorin derivatives which show that the triplet quantum yields of chlorinated derivatives reach unity, whereas those of the fluorinated compounds do not seem to exceed 0.8 [21-23]. All bacteriochlorins studied here activate dihydroethidium (DHE), thereby indicating the presence of a superoxide anion, as shown in Figure 2c. $\mathrm{F}_{2} \mathrm{BOH}$ led to higher activations than $\mathrm{F}_{2} \mathrm{BMet}$ and $\mathrm{Cl}_{2} \mathrm{BHep}$. It will be shown below that, under the same condition, $\mathrm{F}_{2} \mathrm{BOH}$ is substantially decomposed. It is possible that this decomposition affects the probe. The balance between type I (hydroxyl radicals) and type II (singlet oxygen) photochemical mechanisms is thought to play an important role in the PDT activity because the hydroxyl radicals are the most cytotoxic species, and are expected to be a major contributor to tumor damage in PDT. Tookad Soluble [50], which is also a bacteriochlorin derivative, acts mainly 
via type I photochemistry in aqueous media [51,52]. This PS forms both superoxide and hydroxyl radicals upon illumination and the reaction of superoxide with nitric oxide in tumor blood vessels was proposed as the major factor related to the antivascular effect induced by Tookad-V-PDT [51,53]. The propensity of halogenated bacteriochlorins to produce ROS via a type I mechanism was attributed to the formation of a charge-transfer complex with molecular oxygen [3].
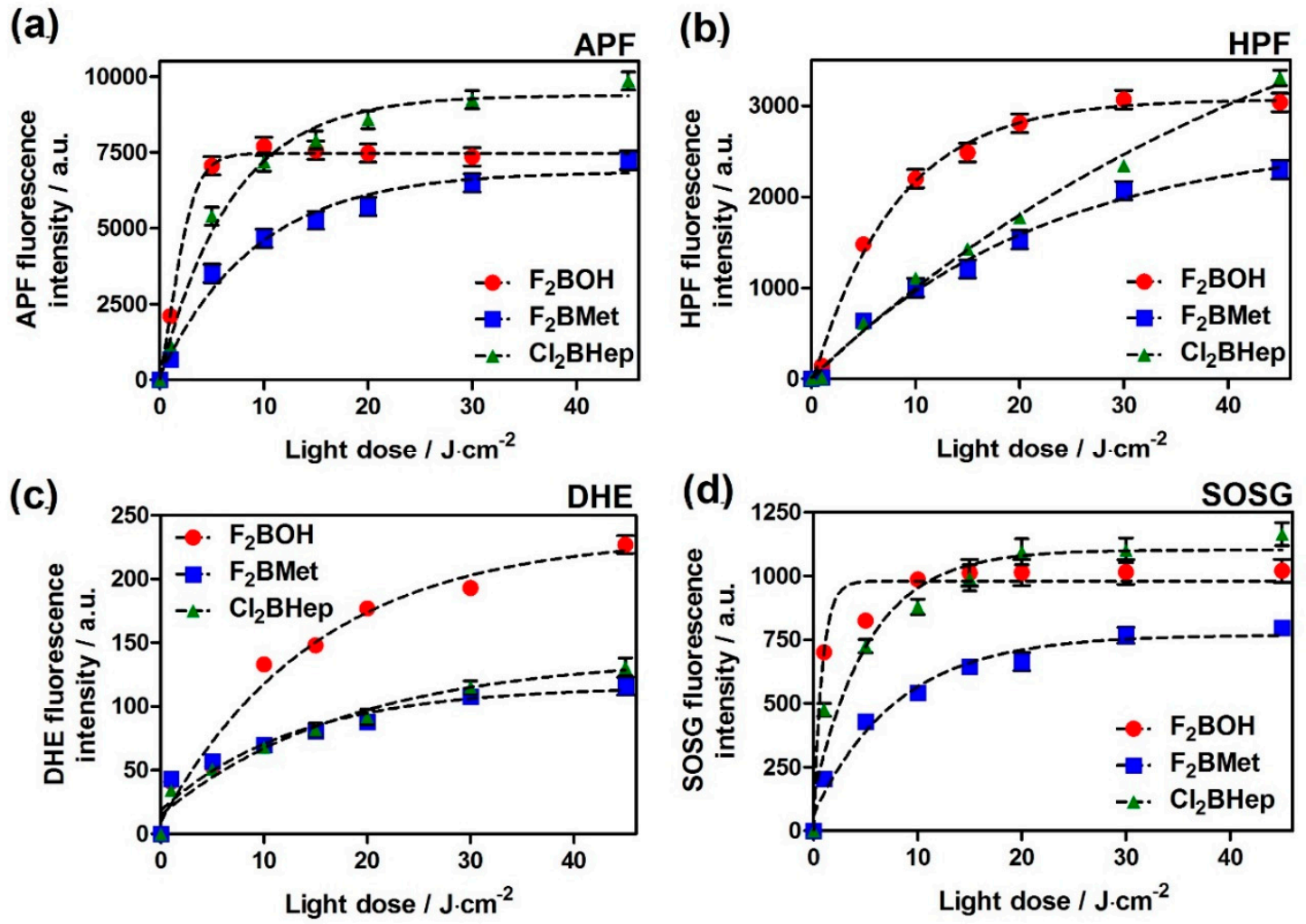

Figure 2. Generation of reactive oxygen species (ROSs) in bacteriochlorin solution (in phosphate-buffered saline (PBS), dimethyl sulfoxide (DMSO) did not exceed $0.5 \%$ ) assessed by the fluorescence probes selective towards: (a) overall radical species (APF), (b) hydroxyl radicals (HPF), (c) superoxide radical anion (DHE) or (d) SOSG specific for singlet oxygen. The concentrations of the probes were initially $10 \mu \mathrm{M}$, and bacteriochlorin was $5 \mu \mathrm{M}$ in each sample. Samples were irradiated with a $735 \pm 20 \mathrm{~nm}$ LED light. Data are presented as mean \pm the standard error of the mean (SEM) $(N=12)$.

\subsection{Photostability}

The photodecomposition quantum yield $\Phi_{\mathrm{pb}}$ is a measure of photostability. According to Table 2, $\mathrm{F}_{2} \mathrm{BOH}$ is the least stable bacteriochlorin of this series. This can also be appreciated in Figure 3. It was shown that bacteriochlorins with phenylsulfonic groups have lower oxidation potentials than bacteriochlorins with phenylsulfonamide groups, and this is associated with more facile oxidation [21-23]. Figure $3 \mathrm{~b}$ shows that the disappearance of the bacteriochorin bands at 375, 510 and $743 \mathrm{~nm}$ is not accompanied by corresponding changes in the shoulder at $410 \mathrm{~nm}$ or in the small band at $660 \mathrm{~nm}$, both assigned to small chlorin contamination in this sample. This suggests that the photodecomposition of $\mathrm{F}_{2} \mathrm{BOH}$ will eventually lead to the opening of the macrocycle. This photodecomposition is likely triggered by the ROS produced by $\mathrm{F}_{2} \mathrm{BOH}$, and may lead to other radical intermediates that react with fluorescent probes, namely DHE. In contrast, the sulfonamide bacteriochlorins are remarkably stable. 
(a)

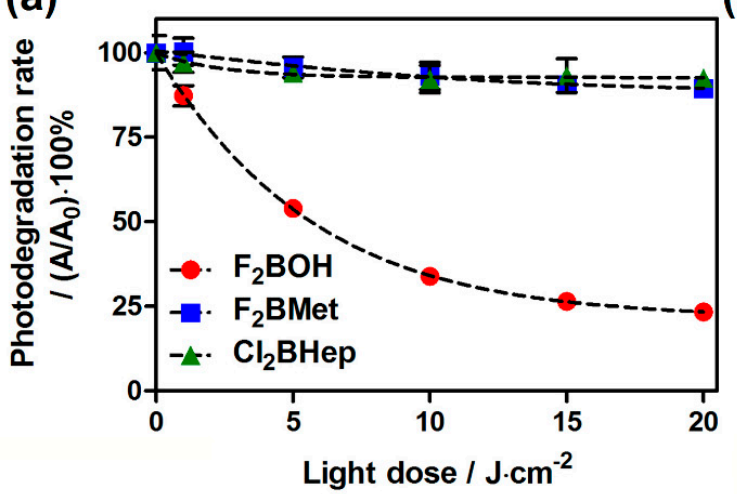

(b)

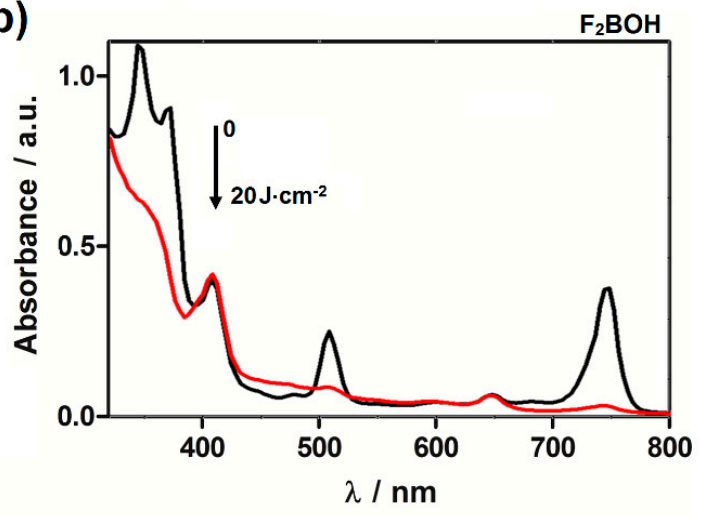

Figure 3. Photostability of sulfonated and sulfonamide bacteriochlorins in PBS solutions (<0.5\% DMSO) under a near-infrared (NIR) light-emitting diode (LED) irradiation: (a) the photodegradation rate; (b) the changes in absorption spectra of $\mathrm{F}_{2} \mathrm{BOH}$ during irradiation.

\subsection{Lipophilicity as Assessed by $\log P$ Determinations}

n-Octanol:PBS partition coefficients are a convenient measure of polarity and are related to solubility in biocompatible solvents. The $P_{\text {OW }}$ values determined using the shake-flask method are presented in Table 2 . The obtained $\log P$ values are similar to those previously reported [48]. The $\log P$ values range from -1.4 to 4.5 , meaning that $\mathrm{F}_{2} \mathrm{BOH}$ is soluble in water, but $\mathrm{Cl}_{2} \mathrm{BHep}$ is insoluble in water. Fluorine and chlorine atoms present in the ortho-position of the phenyl group have a similar effect on the photostability of the studied compounds. On the other hand, substituents in the meta-position determine their hydrophilicity. Therefore, the most hydrophobic compound is a derivative containing $n$-heptyl chain- $\mathrm{Cl}_{2} \mathrm{BHep}$. Moreover, such large differences in polarity are expected to lead to very different biological effects [54].

\subsection{Biological Studies-Optimization of PS Formulation}

Formulations of $\mathrm{F}_{2} \mathrm{BMet}$ in Pluronic poloxamers were recently described [12] and motivated the development of similar formulations fo $\mathrm{Cl}_{2} \mathrm{BHep}$. Absorption spectra of $\mathrm{Cl}_{2} \mathrm{BHep}$ in PBS with $<$ $0.5 \%$ DMSO and encapsulated in polymer micelles are shown in Figure 4. The encapsulation of this bacteriochlorin derivative significantly increases the sharpness of the bands, suggesting disaggregation in P123 micelles. Particle size distribution estimated by DLS (Figure 4b) shows that the hydrodynamic diameter of $\mathrm{Cl}_{2} \mathrm{BHep}-\mathrm{P} 123$ micelles prepared in PBS at pH 7.4 is ca. $27 \mathrm{~nm}$ with a relatively narrow and homogeneous size distribution. Similarly to P123 micelles prepared for $\mathrm{F}_{2}$ BMet described previously [12], the calculated (see equations above) encapsulation efficacy (EE) reached ca. 87\% with 12.12 (wt \%) drug loading content (DL). The zeta potential for $\mathrm{Cl}_{2} \mathrm{BHep}$ was slightly negative and reached $\zeta=-1.07$. These data indicate that $\mathrm{P} 123$ gave the stable structures, with the ability to form micelles and to provide a slightly hydrophobic environment to maintain the photosensitizer in the monomeric form [12]. P123 micelles may increase cellular uptake, efficient photogeneration of hydroxyl radicals, as well as preferable tissue distribution and pharmacokinetics [12]. 
(a)

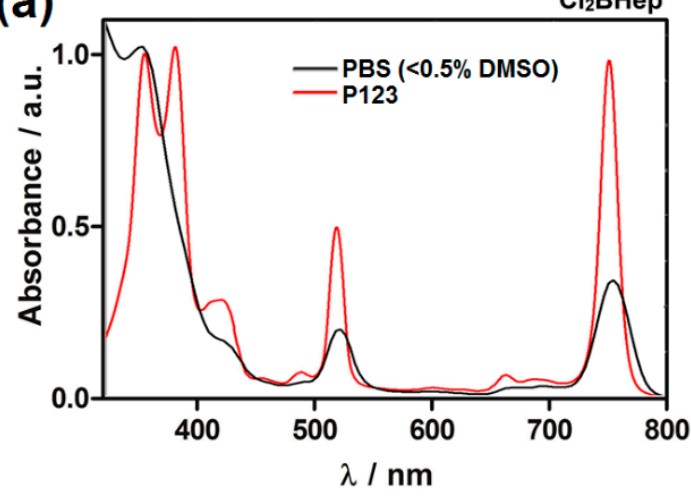

(b)

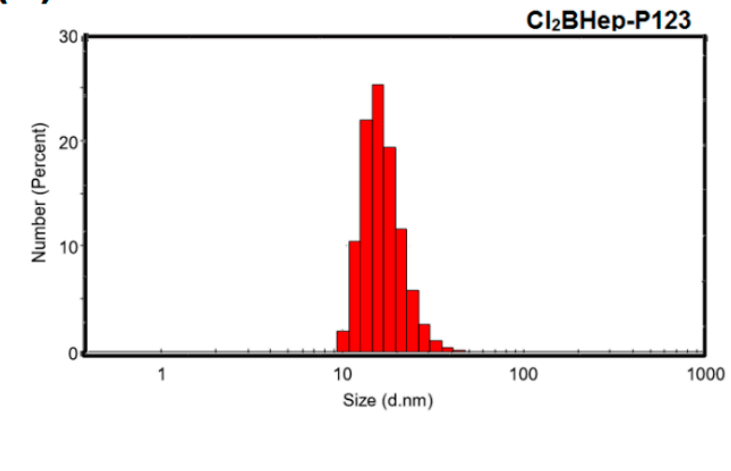

Figure 4. The impact of $\mathrm{Cl}_{2} \mathrm{BHep}$ encapsulation in $\mathrm{P} 123$ micelles: (a) Absorption spectra of $\mathrm{Cl}_{2} \mathrm{BHep}$ registered in PBS (<0.5\% DMSO) and micellar solution in PBS after its encapsulation in Pluronic P123;

(b) particle size distribution of $\mathrm{Cl}_{2} \mathrm{BHep}-\mathrm{P} 123$ measured by dynamic light scattering (DLS).

\subsection{Cellular Uptake of Bacteriochlorins}

The time-dependent accumulation of $\mathrm{F}_{2} \mathrm{BOH}, \mathrm{F}_{2} \mathrm{BMet}$ and $\mathrm{Cl}_{2} \mathrm{BHep}$ (in PBS and in P123 micelles) in CT26 cells exposed to a $5 \mu \mathrm{M}$ photosensitizer solution are shown in Figure $5 \mathrm{a}$.

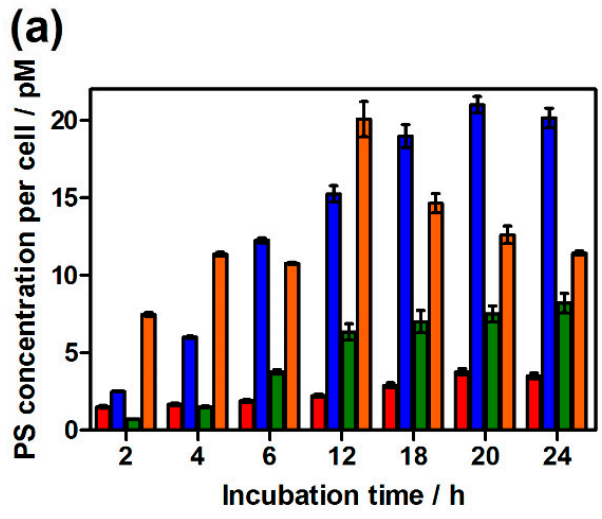

$\mathrm{F}_{2} \mathrm{BOH} \square \mathrm{F}_{2} \mathrm{BMet}$

(c)

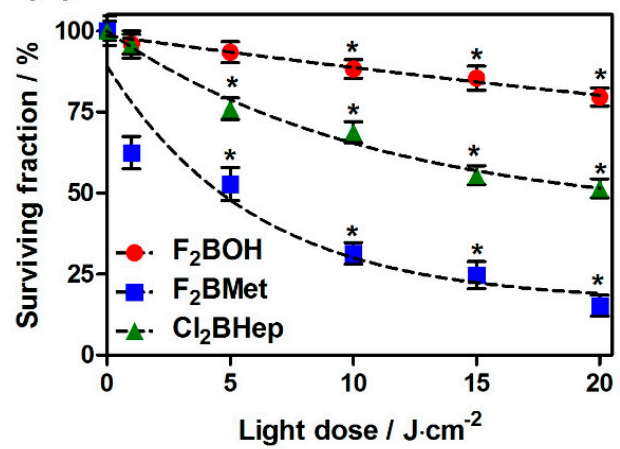

(b)

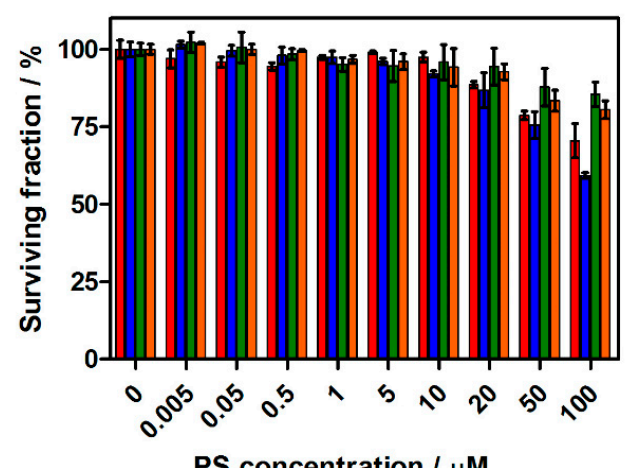

PS concentration $/ \mu \mathrm{M}$

$\mathrm{Cl}_{2} \mathrm{BHep} \square \mathrm{Cl}_{2} \mathrm{BHep}-\mathrm{P} 123$

(d)

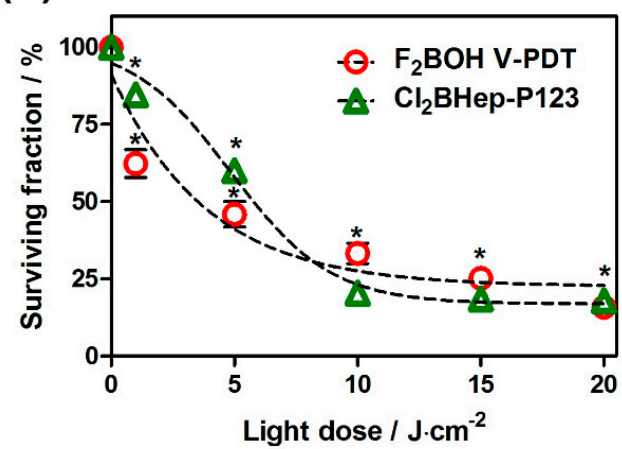

Figure 5. In vitro activity of investigated photosensitizers: (a) time-dependent uptake of halogenated bacteriochlorins at $5 \mu \mathrm{M}$ by CT26 cells determined based on fluorescence measurements of cellular extracts; (b) cytotoxicity in the dark toward CT26 cells determined by MTT assay after optimal incubation time estimated in uptake studies; (c) photodynamic efficacy of $\mathrm{F}_{2} \mathrm{BOH}, \mathrm{F}_{2} \mathrm{BMet}$ and $\mathrm{Cl}_{2} \mathrm{BHep}$ after their incubation at $5 \mu \mathrm{M}$ with CT26 for optimal time and irradiation with $735 \pm 20 \mathrm{~nm}$ LED light; (d) phototoxicity of $\mathrm{F}_{2} \mathrm{BOH}$ at $5 \mu \mathrm{M}$ without washing the medium before illumination, and of $\mathrm{Cl}_{2} \mathrm{BHep}$ encapsulated in P123 micelles at $5 \mu \mathrm{M}$. Data are presented as mean $\pm \operatorname{SEM}(N=12),{ }^{*} p<0.05$. 
The results show that for all tested compounds, a gradual, time-dependent increase in PS accumulation was observed. The optimal accumulation for each bacteriochlorin ranged from 18 to $24 \mathrm{~h}$, and then the uptake decreases, or a plateau phase is observed. $\mathrm{F}_{2}$ BMet $(\log P=1.9)$ showed the most effective accumulation in cells at a concentration of $24 \mathrm{pM}$ per cell after $20 \mathrm{~h}$ of incubation. $\mathrm{F}_{2} \mathrm{BOH}$ is deprotonated in the culture medium $(\log P=-1.4)$, and its negative charges limit its ability to penetrate cell membranes, leading to a relatively low accumulation in cells ( $3.88 \mathrm{pM}$ per cell). For this type of compound, penetration into cells is mainly through the endocytosis. $\mathrm{Cl}_{2} \mathrm{BHep}(\log P \approx 4.5)$ is likely to aggregate in the medium which limits its bioavailability and justifies its low concentration in cells (ca. $7.5 \mathrm{pM}$ ). The encapsulation of $\mathrm{Cl}_{2} \mathrm{BHep}$ in $\mathrm{P} 123$ micelles improves the cellular uptake (22 pM), especially at shorter incubation times (12 h).

The results also indicate very low cytotoxic behavior in the dark in the whole wide range of PS concentrations investigated (Figure $5 b$ ) and pronounced phototoxicity especially for $\mathrm{F}_{2}$ BMet (Figure $5 \mathrm{c}$ ). Based on these data, it can be concluded that without the use of micelles, the largest photodynamic effect was noted for $\mathrm{F}_{2} \mathrm{BMet}$, followed by $\mathrm{Cl}_{2} \mathrm{BHep}$ and finally by $\mathrm{F}_{2} \mathrm{BOH}$. This is also the order of their uptake (Figure 5a). The lower uptake and lower phototoxicity of $\mathrm{F}_{2} \mathrm{BOH}$ can be overcome by illuminating the cells after the incubation with this photosensitizer, but without washing the photosensitizer molecules that remain in the culture medium. This procedure has a close analogy with V-PDT, where the PS is present in the blood, but not inside the cells. The results obtained in these conditions are presented in Figure $5 \mathrm{~d}$ as $\mathrm{F}_{2} \mathrm{BOH}$ V-PDT. The possible aggregation of $\mathrm{Cl}_{2} \mathrm{BHep}_{\mathrm{H}}$ can be avoided using Pluronic formulations. Figure $5 \mathrm{~d}$ also shows that a $\mathrm{P} 123$ formulation of $\mathrm{Cl}_{2} \mathrm{BHep}$ significantly increases its phototoxicity without increasing the cytotoxicity in the dark (Figure 5b) The lethal doses of light causing the killing of $50 \%$ of the cancer cells population $\left(\mathrm{LLD}_{50}\right)$ of the three photosensitizers are presented in Table 3.

Table 3. Lethal light doses (LLD50) of NIR light required to kill 50\% of CT26 determined from surviving curves obtained in phototoxicity studies.

\begin{tabular}{cccccc}
\hline & \multicolumn{5}{c}{ Photosensitizer } \\
\cline { 2 - 6 } & $\mathbf{F}_{2}$ BOH & $\mathbf{F}_{2}$ BOH V-PDE & $\mathbf{F}_{2}$ BMet & Cl $_{2}$ BHep & $\mathbf{C l}_{2}$ BHep-P123 \\
\hline LLD $_{50} / \mathrm{J} \cdot \mathrm{cm}^{-2}$ & - & 4.81 & 4.94 & $>20$ & 5.66 \\
\hline
\end{tabular}

\subsection{Intracellular Localization-CLSM Imaging}

The intracellular localization in CT26 cells of $\mathrm{F}_{2} \mathrm{BOH}, \mathrm{F}_{2} \mathrm{BMet}$ and $\mathrm{Cl}_{2} \mathrm{BHep}$ was investigated by confocal laser scanning microscopy (CLSM). Each of these photosensitizers was incubated with a specific probe for mitochondria (MitoTracker), lysosomes (LysoTracker) and endoplasmic reticulum (ER-Tracker). The intracellular localization of $\mathrm{F}_{2} \mathrm{BOH}$ and $\mathrm{F}_{2} \mathrm{BMet}$ in different cell lines has been published before [21-23,41]. The more hydrophilic bacteriochlorin is accumulated in lysosomes, whereas the amphiphilic bacteriochlorin is mostly found in the ER (and Golgi), with a smaller localization in the mitochondria. The overlapped images corresponding to $\mathrm{Cl}_{2} \mathrm{BHep}$ are shown in Figure 6, in which the fluorescence of the bacteriochlorin is shown in red, and the fluorescence of the organelle-specific probe is shown in green (ER, mitochondria) or in yellow for lysosomes, respectively. The nuclei were also stained with Hoechst 33342 and indicate the characteristic blue fluorescence. The lipophilic $\mathrm{Cl}_{2} \mathrm{BHep}$ possesses a high degree of localization in mitochondria and lysosomes, and a slightly lower one in the ER. The higher subcellular localization of sulfonamide bacteriochlorins in the $\mathrm{ER}$ and mitochondria is consistent with their higher photoxicities than $\mathrm{F}_{2} \mathrm{BOH}$. It is worth to notice that the localization of a photosensitizer is important to determine the initial targets of PDT $[18,55,56]$. 


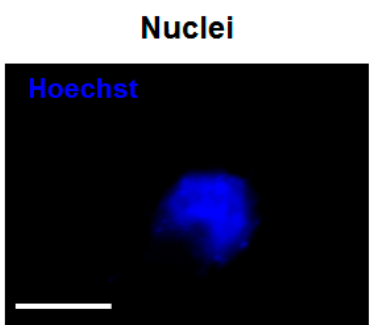

Photosensitizer
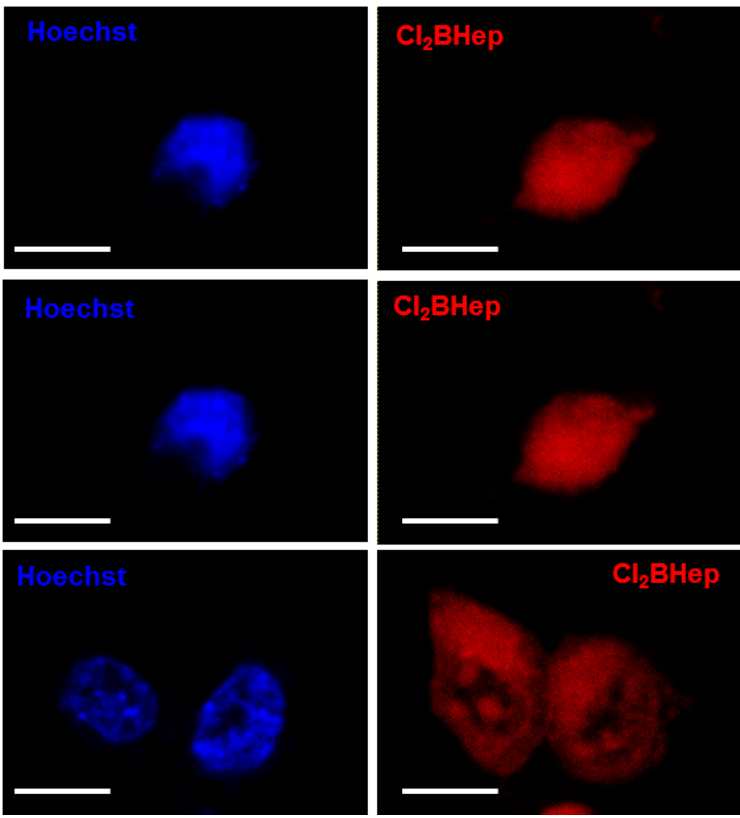
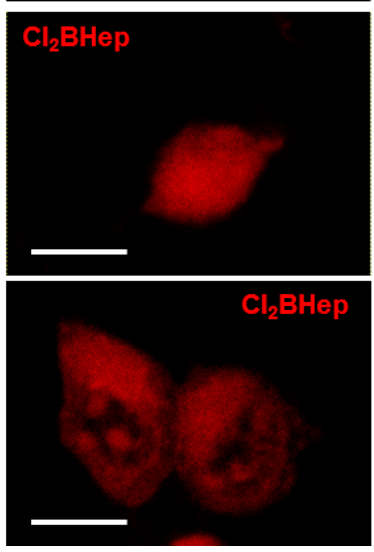

Probe

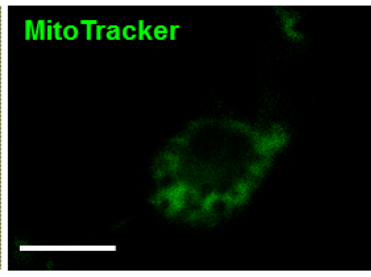

LysoTracker
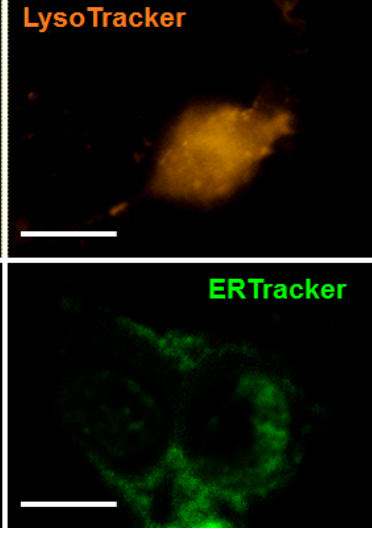

\section{Overlapped}

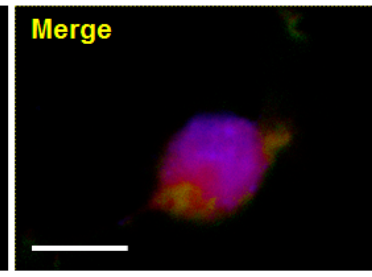

Merge
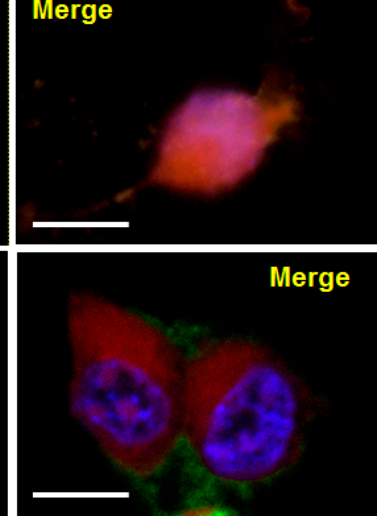

Figure 6. Confocal images of CT26 cells showing intracellular localization of $\mathrm{Cl}_{2} \mathrm{BHep}$ delivered in P123 micelles. Cells were marked with specific probes for mitochondria (Mito-Tracker), lysosomes (Lyso-Tracker) and endoplasmic reticulum (ER-Tracker).

Furthermore, to confirm the colocalization of $\mathrm{Cl}_{2} \mathrm{BHep}$ (red signal) with each organelle-specific probe (green signal) more clearly, the spectral profiles for these components were defined. The obtained profiles are presented in Figure 7.
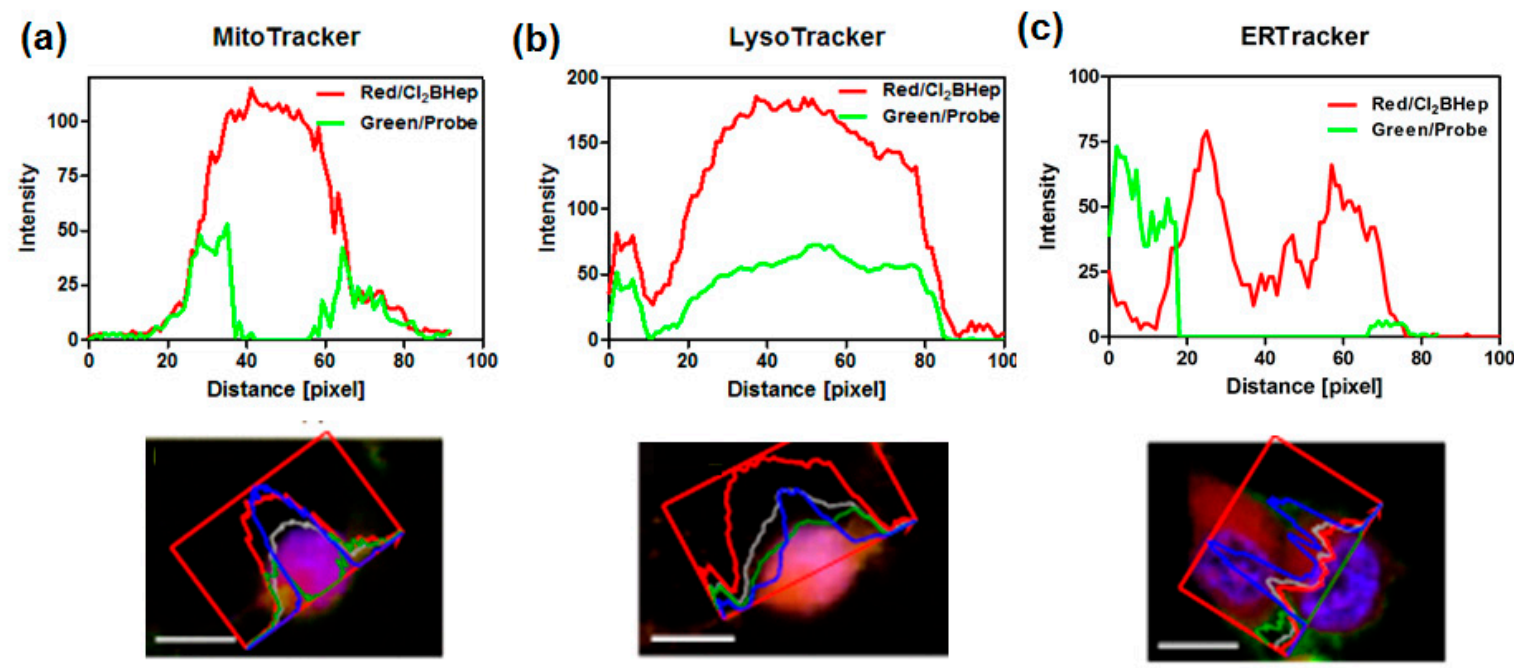

Figure 7. Colocalization of the photosensitizer (PS) and organelle-specific probes (a) MitoTracker, (b) Lysotracker and (c) ERTracker determined and quantified based on the confocal microscopy images and analyzed by ZenSoftware (Zeiss, Jena, Germany).

Localization of hydrophobic PSs in mitochondria may result from the influence of mitochondrial membrane potential and lipid bilayer membrane. Moreover, P123 strongly attenuated the uptake and photocytotoxicity of hydrophobic PSs and redirected the cellular uptake to endocytosis. For example, thiamine pyrophosphate (ThPP) solubilized with P123 was found to accumulate in endocytic vesicles, indicating endocytosis as the main mechanism for the cellular uptake of P123-solubilized THPP. Berg 
and co-workers found that the hydrophobic 5,10,15,20-tetrakis(4-hydroxyohenyl)porphine solubilized with P123 accumulated in endocytic vesicles, and suggested that in this case, the endocytosis is the main mechanism for cellular uptake [57]. The accumulation of the photosensitizer in certain specific organelles (mitochondria, endoplasmic reticulum or Golgi) is thought to lead to the more efficient triggering of cell death upon illumination $[17,18,56]$.

\subsection{In Vivo Studies: PDT Protocol Optimization-Biodistribution}

Biodistribution and pharmacokinetic studies of is done in [24] and amphiphilic $\mathrm{F}_{2}$ BMet $[15,22]$ were reported recently, and reveal the highest tumor-to-muscle or -to-skin ratio immediately after PS intravenous administration $[15,22,24] . \mathrm{F}_{2} \mathrm{BOH}$ is characterized by high blood concentration after intravenous administration, relatively low tissue accumulation and rapid elimination time (44 h). Its i.v. injection does not require the use of any carriers and is done in PBS [24]. On the other hand, $\mathrm{F}_{2}$ BMet is effectively administered in micellar form based on the low content of the solubilizer CrEL $(\mathrm{CrEL} / \mathrm{EtOH} / 0.9 \% \mathrm{NaClaq}$ 0.2:1:98.8 $v / v / v)$, indicating appropriate tissue distribution in many types of tumors $[12,15,22,24] .15$ min after administration it shows high blood concentration, which decreases with time, and good affinity to cancer tissues. It is characterized by a slightly longer stay in the body (about 65 h) $[15,24]$

The tissue distribution of $\mathrm{Cl}_{2} \mathrm{BHep}$ is described for the first time and is presented in Figure 8. The tissue distribution of $\mathrm{Cl}_{2} \mathrm{BHep}$ was determined using the extraction of tissue and biological fluids followed by homogenization and fluorescence measurements.

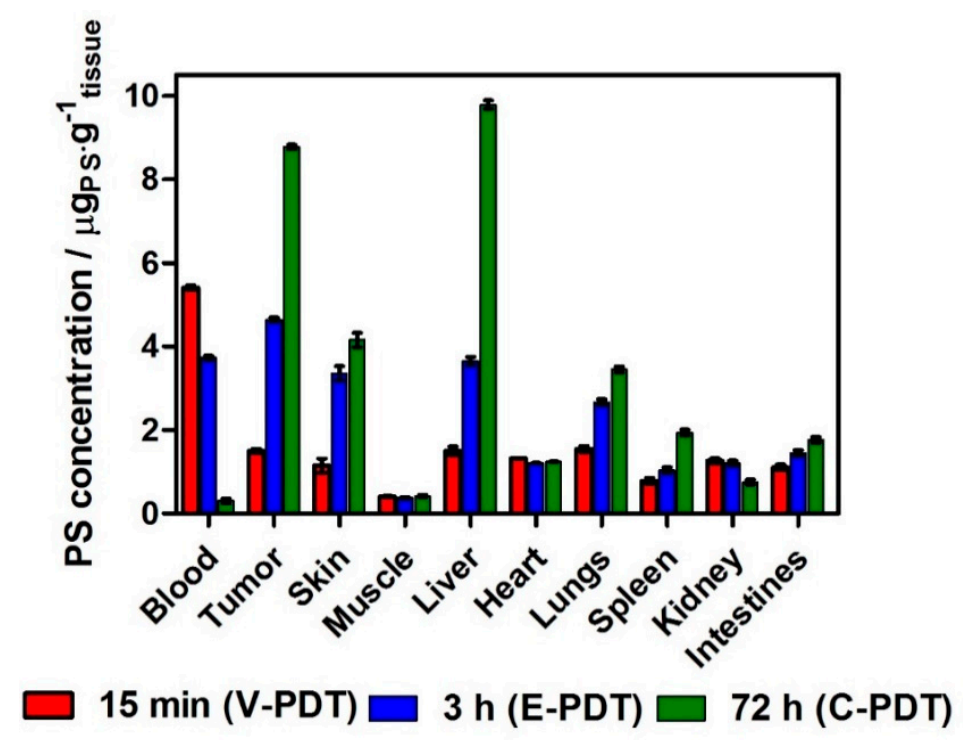

Figure 8. Biodistribution of $\mathrm{Cl}_{2} \mathrm{BHep}$ encapsulated in $\mathrm{P} 123$ micelles in organs and tissues extracted from BALB/c mice bearing CT26 tumors determined at various periods of time after the injection. The data are presented as mean $\pm \operatorname{SEM}(N=6)$.

The results clearly indicate that this hydrophobic PS can be favorable in C-PDT due to the significantly increased tumor accumulation in the prolonged incubation time (especially $72 \mathrm{~h}$ after PS injection). At this point, the PS concentration in tumors is four times higher than that obtained for 15 $\mathrm{min}$, and the double of that for $3 \mathrm{~h}$. The calculated tumor to muscle (T:M) ratios at $15 \mathrm{~min} ., 3 \mathrm{~h}$ and $72 \mathrm{~h}$ are 3.6, 12.5 and 20.9, respectively. The tumor to skin (T:S) ratios are equal to 1.3, 1.38 and 2.11 at the same time. The highest T:M and T:S ratios at $72 \mathrm{~h}$ suggest a superior selectivity for $\mathrm{Cl}_{2} \mathrm{BHep}$ and a remarkable potential for cellular-targeted protocols with DLI $=72 \mathrm{~h}$ (C-PDT).

The summary of the photosensitizers' properties crucial for optimization and appropriate choice of PDT protocols, as well as their systemic administration, are listed in Table 4. 
Table 4. Properties of investigated bacteriochlorin-based photosensitizers and those used in clinical practice, crucial for determining the photodynamic therapy (PDT) protocols in vivo.

\begin{tabular}{cccccc}
\hline Photosensitizer & $\log \mathbf{P}$ & Tumor uptake & PK/Circulation Time & DLI & Formulation \\
\hline $\mathrm{F}_{2} \mathrm{BOH}[24]$ & -1.4 & $3.69 \mathrm{pM}$ per cell & $44 \mathrm{~h}$ & $15 \mathrm{~min}(\mathrm{~V}-\mathrm{PDT})$ & $0.9 \% \mathrm{NaCl}$ \\
$\mathrm{F}_{2} \mathrm{BMet}[15,22]$ & 1.9 & $24 \mathrm{pM}$ per cell & $65 \mathrm{~h}$ & $\mathrm{CrEL}: \mathrm{PBS}$ \\
$\mathrm{Cl}_{2} \mathrm{BHep}$ & 4.5 & $7.5 \mathrm{pM}$ per cell & $<96 \mathrm{~h}$ & $72 \mathrm{~h}(\mathrm{C}-\mathrm{PDT})$ & $\mathrm{Pluronic} \mathrm{P} 123$ \\
Tookad Soluble [58] & $>1.0$ & max. $50 \mathrm{pg} / \mathrm{mg}$ protein & $\max 1 \mathrm{~h}$ & $>15 \mathrm{~min}(\mathrm{~V}-\mathrm{PDT})$ & $0.9 \% \mathrm{NaCl}$ \\
Photofrin $[59,60]$ & $<0.15$ & max. $1.6 \mu \mathrm{g} / \mathrm{mg}$ protein & $144 \mathrm{~h}$ & $6-24 \mathrm{~h}(\mathrm{C}-\mathrm{PDT})$ & $\mathrm{Saline}+5 \%$ glucose \\
\hline
\end{tabular}

\subsection{PDT Efficacy}

We investigated the three basic PDT protocols, involving drug-to-light intervals of $15 \mathrm{~min}$ (V-PDT), $3 \mathrm{~h}$ (E-PDT) and $72 \mathrm{~h}$ (C-PDT) between the injection of the photosensitizer and the illumination. V-PDT aims at the destruction of tumor vessels, limiting the tumor nutrition and controlling tumor growth. In V-PDT, light is applied very soon after PS administration, while it is still within the vascular compartment. This protocol was tested for all the photosensitizers because all of them are mostly in the vascular compartment $15 \mathrm{~min}$ after i.v. administration. Alternatively, in tumor endothelial cells-targeted PDT (E-PDT), the drug-to-light interval is increased up to $3 \mathrm{~h}$ to take advantage of the accumulation of the photosensitizer both in the tumor microenvironment and tumor tissue. C-PDT with DLI $=72 \mathrm{~h}$ aims at the selective destruction of the tumor tissue while sparing the normal tissues. The latter two protocols were not tested for $\mathrm{F} 2 \mathrm{BOH}$ because of its faster elimination from the organism. Figure 9 shows the Kaplan-Meier survival plots for all protocols with an indication of the percentage of animals with local tumor control.

(a)

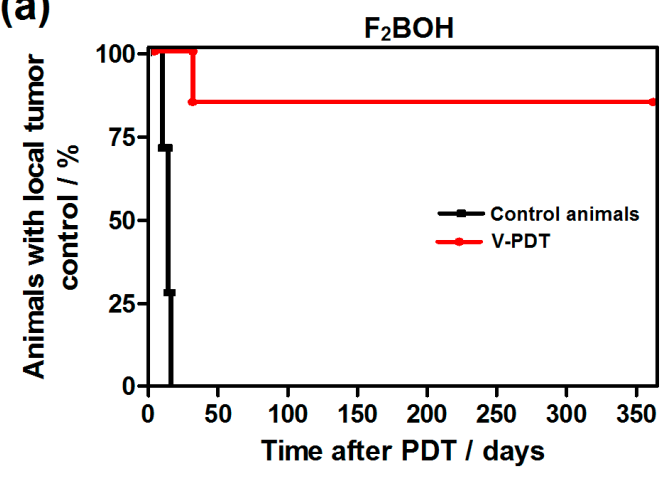

(c)

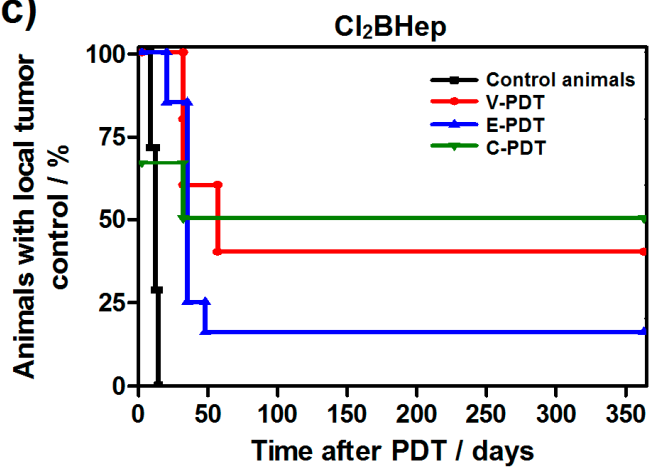

(b)

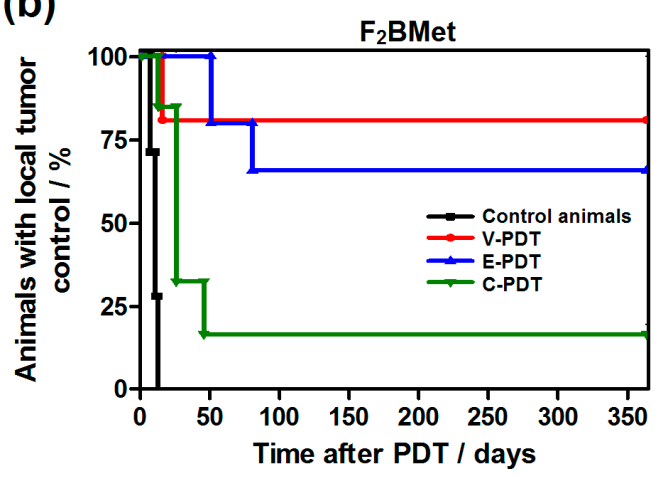

(d)

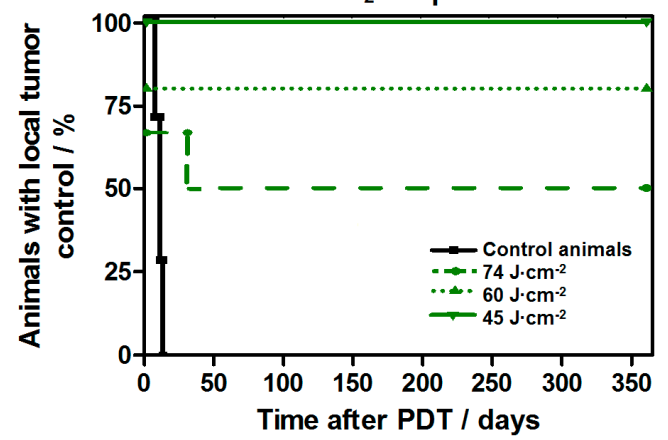

Figure 9. Kaplan-Meier curves of CT26 tumor regrowth after PDT treatment with: (a) $\mathrm{F}_{2} \mathrm{BOH}$ V-PDT; (b) $\mathrm{F}_{2}$ BMet V-PDT, E-PDT and C-PDT; (c) $\mathrm{Cl}_{2}$ BHep V-PDT, E-PDT and C-PDT; in all cases the tumor-bearing mice $(N=6-7)$ were irradiated with $74 \mathrm{~J} / \mathrm{cm}^{2}$ dose of NIR laser light $(130 \mathrm{~mW}, 748 \mathrm{~nm})$ at $15 \mathrm{~min}, 3 \mathrm{~h}$ or $72 \mathrm{~h}$ post-IV injection of $1.5 \mathrm{mg} / \mathrm{kg}$ drug dose. (d) presents the surviving data obtained for $\mathrm{Cl}_{2} \mathrm{BHep}$-C-PDT after application of different laser light doses (light-dose de-escalation study) and $1.5 \mathrm{mg} / \mathrm{kg}$ drug dose. 
Figure 9 shows that tumor growth control was observed in all groups. For F2BOH-V-PDT (Figure $9 \mathrm{a}$ ), complete long-term remission was obtained for $85 \%$ of the treated animals. In the case of $\mathrm{F}_{2} \mathrm{BMet}$ (Figure $9 \mathrm{~b}$ ), the V-PDT protocol was also the most effective, resulting in about $80 \%$ of total cures. The $\mathrm{F}_{2} \mathrm{BMet}-\mathrm{E}-\mathrm{PDT}$ was also highly effective, resulting in $65 \%$ long-term cures. $\mathrm{F}_{2} \mathrm{BMet}$ C-PDT was less successful, with only $20 \%$ of cured mice. Interestingly, results obtained for the most hydrophobic photosensitizer $\mathrm{Cl}_{2}$ BHep encapsulated in Pluronic P123 micelles indicate the highest percentage of cures, especially after C-PDT (Figure $9 \mathrm{c}, \mathrm{d}$ ). $\mathrm{Cl}_{2} \mathrm{BHep}$ C-PDT with $74 \mathrm{~J} / \mathrm{cm}^{2}$ led to a very strong systemic inflammatory response that led to the death of some treated mice $(35 \%)$ in the first $24 \mathrm{~h}$ after treatment (thus, survival analysis in Figure $8 \mathrm{c}$ starts at 65\%). Subsequently, the light dose was de-escalated to obtain a safe protocol. C-PDT with a light dose of $60 \mathrm{~J} / \mathrm{cm} 2$ remained lethal for $40 \%$ of the mice. A light dose of $45 \mathrm{~J} / \mathrm{cm} 2$ no longer caused strong inflammatory reactions, and long-term cures were obtained for all of the animals. This is one of the most remarkable results with C-PDT protocols at such low light doses. The efficiency of Cl2BHep-C-PDT may be the result of the synergistic interaction of the following factors: (1) the formulation based on the PluronicP123 polymer; (2) appropriate accumulation of the photosensitizer in tumor tissue, which was demonstrated in a tissue distribution study; (3) efficient generation of ROSs, including type I mechanism.

\subsection{The Inflammatory Changes Observed after PDT}

The PDT efficacy presented in the Kaplan-Meier plots indicates that the hydrophilic PS is most effective in V-PDT, the amphiphilic compound is suitable for both V- and E-PDT and the hydrophobic one shows superior activity in C-PDT. It is interesting to further explore the biological responses of these protocols and their possible connection with the very diverse therapeutic outcomes.

We observed differences in acute biological responses to PDT, such as edema and erythema, in vascular and cellular protocols (Figure 10). Edema usually appeared immediately after V-PDT and E-PDT, attained its maximum $24 \mathrm{~h}$ post-treatment and lasted until day 3-4. However, strong erythema and hyperemia were only present in animals subjected to F2BOH-V-PDT. For F2BMet-V-PDT the illumination area is characterized by large swelling, whereas after Cl2BHep-C-PDT, any strong edema is not observed. In the case of the F2BMet-V-PDT edema of the leg with the tumor, which was maximal at $3 \mathrm{~h}$ then decreased up to day 4 , and then the progressive darkening of the tumor and scab formation are observed. For C-PDT, the inflammatory changes appear milder without significant edema, and tumor involution occurs over a prolonged period with the increase in necrotic area, as opposed to the acute effects observed with V-PDT. The different therapeutic protocols seem to generate a different immune response, which is likely to influence the therapeutic outcome.

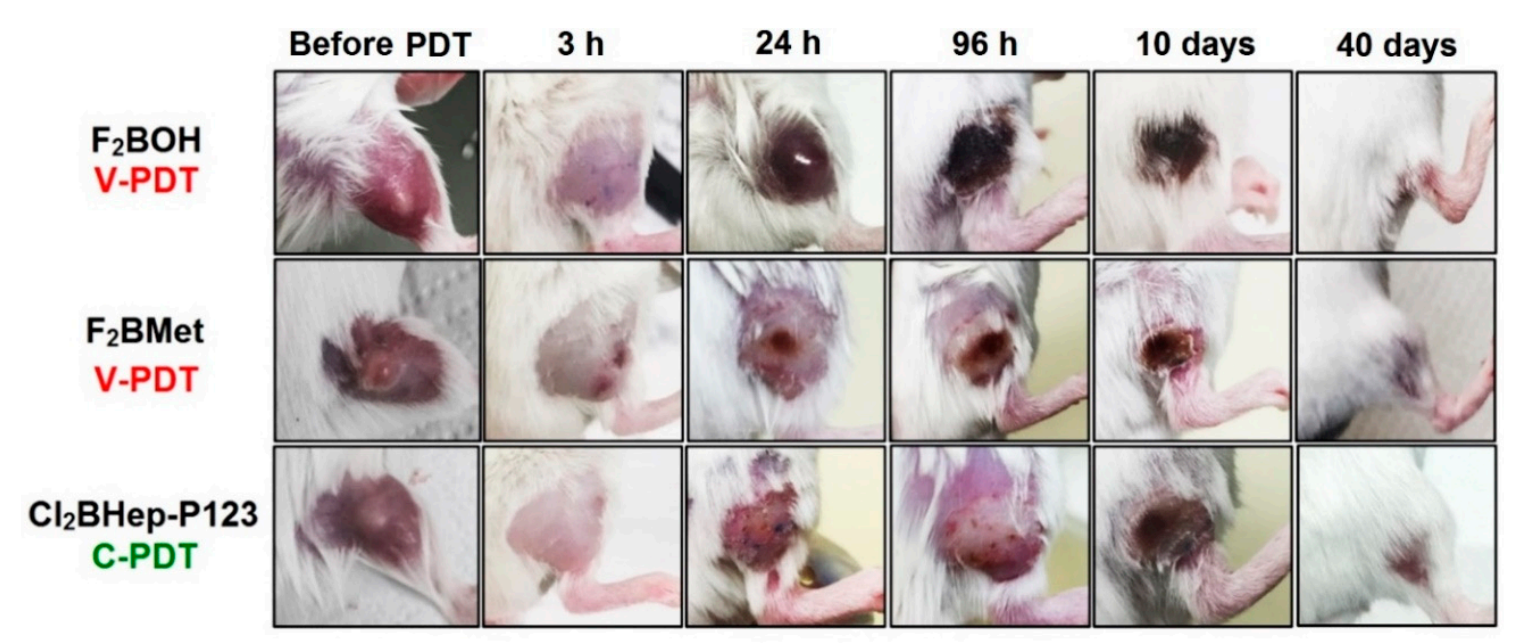

Figure 10. The differences in the inflammatory reaction occurring in $\mathrm{BALB} / \mathrm{c}$ mice bearing $\mathrm{CT} 26$ tumors before and after PDT using optimal protocols with F2BOH, F2BMet, and Cl2BHep as the photosensitizer. 


\subsection{Examination of Inflammatory Cytokines Changes Induced by PDT}

We further explored the inflammatory responses observed with different PSs and protocols evaluating changes in selected cytokines and proinflammatory mediators present in the blood before and $24 \mathrm{~h}$ after PDT using the Luminex xMAP technology, as shown in Scheme 2. The results in terms of observed trends in all tested biomarkers changes are presented in Table 5 . These biomarkers can inform on the degree and mode of inflammation, infiltration of neutrophils, tumor cell death, as well as the destruction of the vasculature [61]. A first overview identifies common trends such as significant increases in IL- 6 or KC, and tendencies to increase IL-10, MIP-2, MIP-1 $\beta$ or TNF $\alpha$. However, there are also differences between the protocols.

Table 5. The trend in changes of selected cytokines and chemokines determined after bacteriochlorin-based PDT. The analysis was performed using Luminex multiplexing assay in the serum of individual mice before and after PDT $(\mathrm{N}=6-7)$.

\begin{tabular}{|c|c|c|c|c|c|c|c|}
\hline \multirow{2}{*}{$\begin{array}{c}\text { PS } \\
\text { Cytokine }\end{array}$} & \multirow{2}{*}{$\begin{array}{c}\text { F2BOH } \\
\text { V-PDT }\end{array}$} & \multicolumn{3}{|c|}{ F2BMet } & \multicolumn{3}{|c|}{ СІ2ВНер } \\
\hline & & V-PDT & E-PDT & C-PDT & V-PDT & E-PDT & C-PDT \\
\hline IL-6 & 1 1 & 1 & 1 & 1 & 1 & 1 1 & 1 \\
\hline IL-10 & 仓े & - & 仓 & 仓 & 仓े & - & $\boldsymbol{1}$ \\
\hline IL-13 & 1 & $\sqrt{2}$ & $\sqrt{3}$ & - & -1 & 1 & 仓 \\
\hline IL-15 & 仓 & 仓 & - & 仓 & $\boldsymbol{1}$ & $\boldsymbol{1}$ & 1 \\
\hline $\mathrm{KC}$ & 1 & 1 & 1 & 1 & 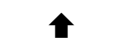 & 1 1 & 1 \\
\hline MIP-2 & 1 & - & 1 & 1 & - & $\boldsymbol{1}$ & 仓 \\
\hline LIX & 1 & $\sqrt{3}$ & $\sqrt{2}$ & - & - & ת & ת \\
\hline LIF & 仓 & 仓 & 仓 & - & - & - & 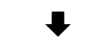 \\
\hline MCP-1 & 1 & - & 1 & 1 & 1 & 仓े & 1 \\
\hline MIP-1 $\alpha$ & - & 수 & 1 & - & - & 仓 & ת \\
\hline MIP-1 $\beta$ & $\sqrt{2}$ & - & 1 & - & - & 仓 & $\sqrt{2}$ \\
\hline IP-10 & 1 & - & 1 & - & $y$ & - & 1 \\
\hline MIG & ㅅ & 1 & $\sqrt{t}$ & - & 1 & - & - \\
\hline GM-CSF & 仓 & - & $\sqrt{3}$ & - & - & - & - \\
\hline VEGF & 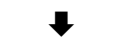 & $\downarrow$ & - & - & 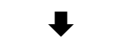 & - & $\sqrt{3}$ \\
\hline $\mathrm{TNF} \alpha$ & 1 & 1 & 仓े & - & - & - & 1 \\
\hline
\end{tabular}

indicated significantly (min two-times) increased or decreased the level of each biomarker, 仓 and § are symbols for the non-significant (higher or lower) tendency in the concentration of biomarker. The tendencies were estimated in comparison to values obtained in the serum of the same individual animals before PDT.

Figure 11 focuses on the changes observed in the blood levels of interleukins. A significant increase in the concentration of IL- 6 was observed in all cases (Figure 11a). The multidirectional nature of IL-6 interactions includes the participation in the activation of antigen-recognizing T lymphocytes (also LIF) as well as the production of acute-phase proteins indicating the early reaction in response to tissue damage. IL-6 expression was strongly and consistently enhanced in PDT-treated mice, although the role of IL-6 in PDT-induced inflammation may vary depending on the PS, protocol or type of tumor treated [61-63]. Increased IL-6 concentration in plasma can be considered as early and sensitive, although nonspecific, indicators of various inflammations, which in this case should be identified with the destruction of tumor tissue [64]. 
(a)

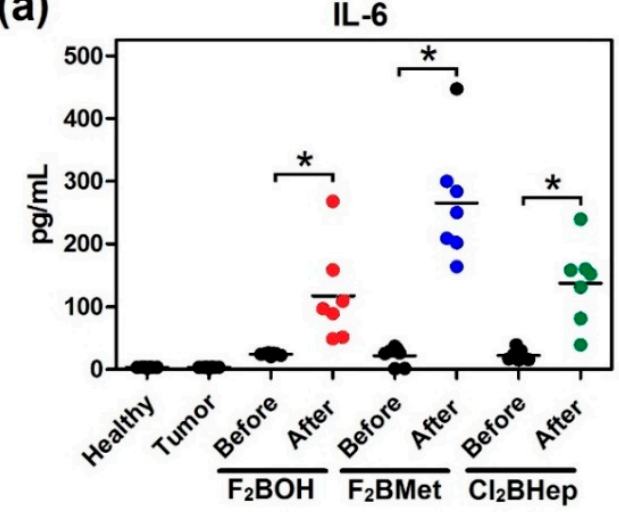

(c)

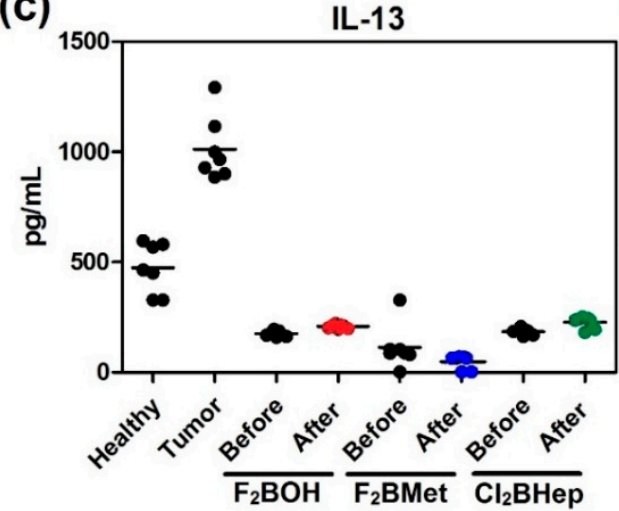

(b)

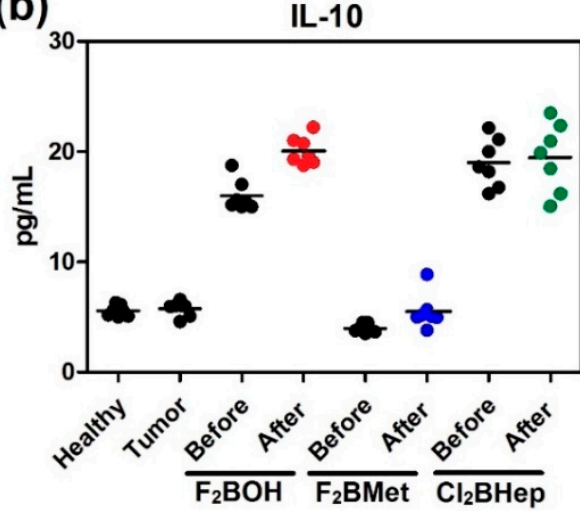

(d)

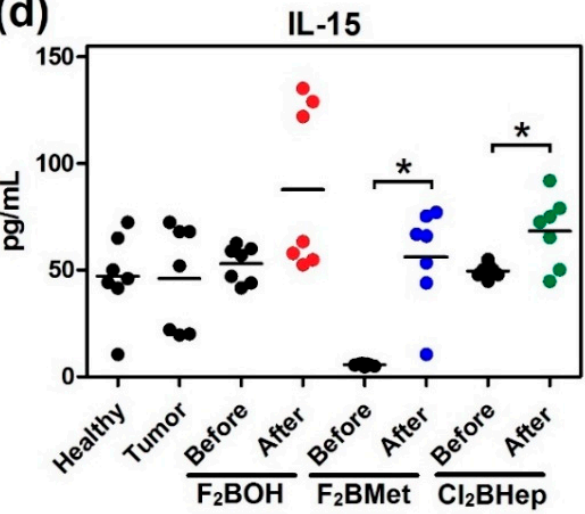

Figure 11. Concentrations of selected interleukins: (a) IL-6; (b) IL-10; (c) IL-13; (d) IL-15 in the serum of mice before and after optimal PDT protocol with $\mathrm{F}_{2} \mathrm{BOH}$ (V-PDT), $\mathrm{F}_{2} \mathrm{BMet}$ (V-PDT) and $\mathrm{Cl}_{2} \mathrm{BHep}$ (C-PDT) as well as healthy mice and mice bearing CT26 tumor controls. Luminex, N = 6-7; each dot represents one individual, line represents a mean; ${ }^{*} p<0.05$.

In the experimental groups that underwent PDT, these also exhibited a significant increase in IL-15 level, Figure 11d. In cancer immunotherapy, this cytokine is considered as a strong adjuvant, stimulating cytotoxicity and the proliferation of lymphocytes (cytotoxic, NKT) as well as the proliferation and secretion of antibodies activated by B cells [65]. IL15 is also an important growth factor for memory T lymphocytes, especially CD8+ [66]. The lack of unambiguous changes in IL-13 and especially in IL-10 (with the possible exception of $\left(\mathrm{F}_{2} \mathrm{BOH}\right)$, the V-PDT concentration after PDT (Figure 10b) using most protocols can be considered a good prognostic factor because it can ultimately lead to inhibition of the cell-type immune response and inflammatory processes [67]. In this respect, $\mathrm{F}_{2} \mathrm{BOH}$ V-PDT may not provide the best control of the inflammatory process. An increase in the concentration of CC-type chemokines (MCP-1, MIP1 $\alpha$, MIP1 $\beta$ ) in the plasma after PDT can be seen (except for the $\mathrm{F}_{2}$ BMet V-PDT and C-PDT protocol). A significant increase in the concentration of the inflammatory protein MCP-1 is evidence of increased inflammatory processes within the tumor microenvironment and the dominance of the necrotic pathway of cancer cell death and the infiltration of macrophages and monocytes into the tumor surrounding tissue $[68,69]$.

Several preclinical studies have suggested that suppression of long-term tumor growth following Photofrin-PDT is dependent upon the presence of neutrophils [70]. Neutrophil migration into the treated tumor is associated with an increase in the expression of the chemokines macrophage inflammatory protein MIP-2 and KC. Figure 12 shows that MIP-2 and KC increase significantly after PDT. In particular, V-PDT with both $\mathrm{F}_{2} \mathrm{BOH}$ and $\mathrm{F}_{2} \mathrm{BMet}$ causes a large increase in $\mathrm{KC}$ that is constitutively expressed and is believed to be involved in basal neutrophil migration. In contrast, MIP-2, the major chemokine released after $\mathrm{F}_{2}$ BMet-V-PDT, is inducible and thought to mediate stressor injury-induced neutrophil migration. 
(a)

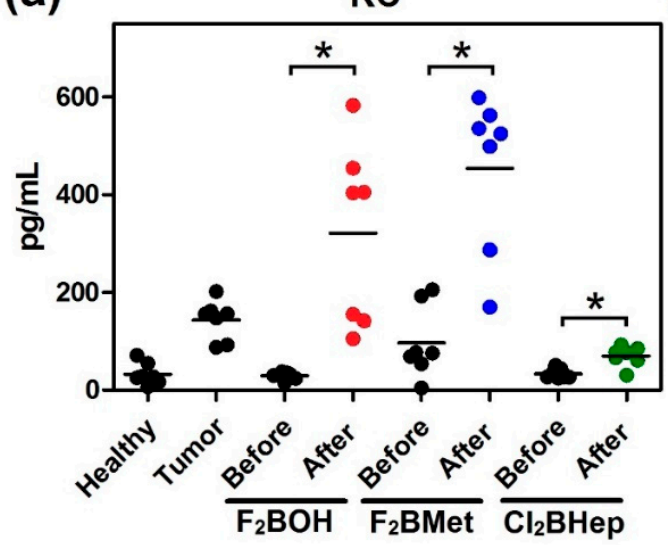

(b)

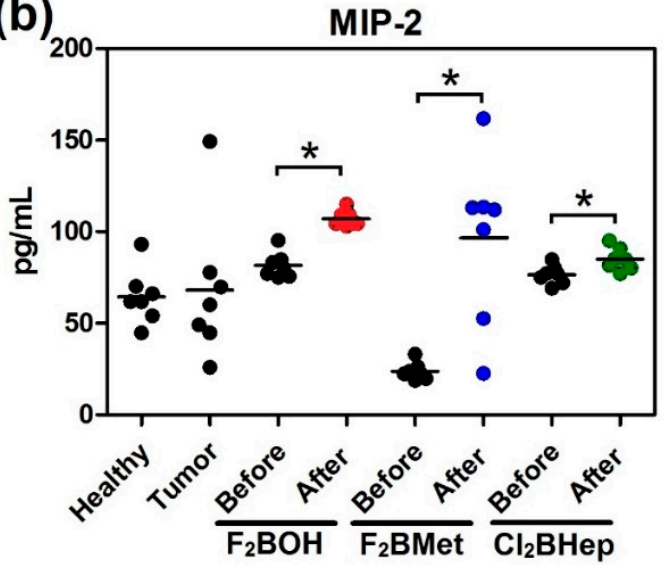

Figure 12. Concentrations of selected neutrophil chemokine attractants: (a) KC; (b) MIP-2; in the serum of mice before and after optimal PDT protocol with $\mathrm{F}_{2} \mathrm{BOH}(\mathrm{V}-\mathrm{PDT}), \mathrm{F}_{2} \mathrm{BMet}$ (V-PDT) and $\mathrm{Cl}_{2} \mathrm{BHep}$ (C-PDT), as well as healthy mice and mice bearing CT26 tumor controls. Luminex, $N$ = 6-7; each dot represents one individual, line represents a mean; ${ }^{*} p<0.05$.

The levels of KC and MIP-2 were unchanged in non-treated CT26 tumor-bearing mice and remained the comparable levels before PDT, which additionally indicates that the induction of MIP-2 and KC was not the result of a systemic mediator. Thus, bacteriochlorin-mediated V-PDT induced a time-dependent increase in two neutrophil attractant chemokines, MIP-2 and KC.

The optimal protocols with sulfonamide bacteriochlorin $\left(\mathrm{F}_{2} \mathrm{BMet}-\mathrm{V}-\mathrm{PDT}\right.$ and $\left.\mathrm{Cl}_{2} \mathrm{BHep}-\mathrm{C}-\mathrm{PDT}\right)$ are characterized by increased secretion of MIP-1, which is also involved in neutrophilic inflammation. Only in the case of $\mathrm{F}_{2} \mathrm{BOH}-\mathrm{V}-\mathrm{PDT}$ can the higher level of MIG (CXCL9) and IP-10 (CXCL10) be detected [71]. Importantly, these chemokines are known to exhibit antitumor activity through strong T-cell chemotaxis and anti-angiogenic (angiostatic) properties. Thus, due to the fact that their production is induced by interferons (IFN $\gamma$, inducible protein 10, IP-10, IFN $\gamma$-induced chemokine monokine 9, MIG), their increased plasma concentration after PDT indirectly indicates the activity of IFN $\gamma$ [72].

Figure 13 shows how TNF $\alpha$ had increased in the blood of all groups that were subjected to the optimal scheme of PDT. It is widely known that $\mathrm{TNF} \alpha$ upregulation may induce changes in the tumor vasculature and stimulate the antitumor immune response [73]. Moreover, these data can also suggest the activity of macrophages triggering in these cells Toll-like receptor (TLR)-based signal transduction activity resulting in the production of TNF $\alpha[61,62]$.

(a)

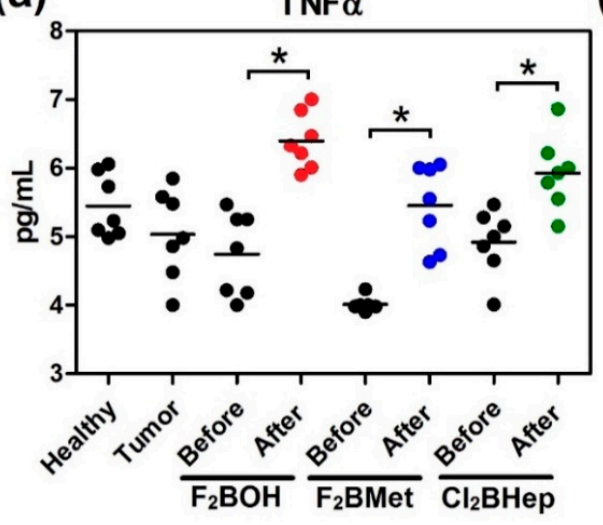

(b)

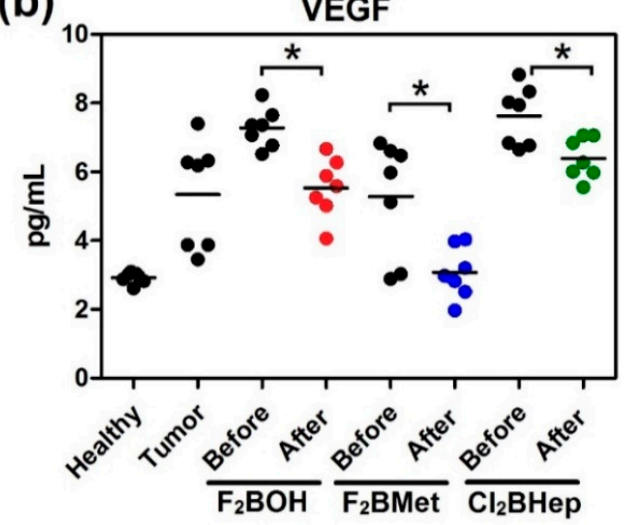

Figure 13. Concentrations of (a) TNF $\alpha$; (b) VEGF in the serum of mice before and after optimal PDT protocol with $\mathrm{F}_{2} \mathrm{BOH}$ (V-PDT), $\mathrm{F}_{2} \mathrm{BMet}(\mathrm{V}-\mathrm{PDT})$ and $\mathrm{Cl}_{2} \mathrm{BHep}(\mathrm{C}-\mathrm{PDT})$ as well as healthy mice and mice bearing CT26 tumor controls. Luminex, $N=6-7$; each dot represents one individual, line represents a mean; ${ }^{*} p<0.05$. 
Last, but not least, we examined the vascular endothelial growth factor (VEGF). Figure 12b reveals a more significant decrease of VEGF after vascular-targeted treatment than after C-PDT. This observation suggests that the formation of new vessels within the tumor is inhibited, thereby stopping its further local progression and preventing distant metastases [74].

Taken together, the inflammatory changes observed after PDT and the patterns of inflammatory cytokines changes reveal that water-soluble photosensitizers such as $\mathrm{F}_{2} \mathrm{BOH}$, generally lead to an increase in the serum level of these cytokines in V-PDT, when compared with less polar photosensitizers. This is consistent with the observation of strong erythema and hyperemia in animals subject to $\mathrm{F}_{2} \mathrm{BOH}-\mathrm{V}-\mathrm{PDT}$. This may be related to the preferential association of hydrophilic photosensitizers with albumin, as opposed to the association of the less polar photosensitizers with lipoproteins. The tumor localization of albumin-bound and lipoprotein-bound photosensitizers is likely the cause of the difference in inflammatory reactions, because in the conditions of this study (same drug and light doses, comparable tumor concentration in V-PDT), all the photosensitizers produce similar oxidative stresses (similar light absorption and similar singlet oxygen quantum yields). Interestingly, the cytokine patterns revealed that V-PDT, E-PDT and C-PDT with $\mathrm{F}_{2}$ BMet are surprisingly similar, although the photosensitizer concentration in the target tissue decreases appreciably with time. This suggests that the re-localization of the photosensitizer in the tumor may compensate for its lower concentration to yields-comparable inflammatory responses.

\section{Summary and Conclusions}

We determined physicochemical, spectroscopic and photochemical properties of three bacteriochlorins with widely different polarities (F2BOH, F2BMet, Cl2BHep), and related them with phototoxicity in vitro and PDT efficacy in prototypical PDT regimes. The most important difference between the studied compounds is their hydrophilicity/lipophilicity $(\log \mathrm{P})$ caused by a change from sulfonic group, to methylsulfonamide and to heptylsulfonamide ones, respectively. For the reasons discussed above, the chlorinated substituent has a higher singlet oxygen quantum yield $\left(\Phi_{\Delta}=0.63\right.$ ) than the fluorinated compounds ( $\Phi_{\Delta}$ ranged from 0.43 to 0.44$)$, but this does not make Cl2BHep more phototoxic in vitro. The advantage of having chlorine atoms in the least soluble compound is to help avoid aggregation. The bulky chlorine atoms prevent the bacteriochlorins from sitting on the top of each other and facilitating dissolution.

PDT in vitro is influenced by differences in cellular uptake and subcellular localization. The pharmacokinetics and biodistribution of the photosensitizers determine the PDT regime (V-PDT, E-PDT, C-PDT) most adequate for each one of them. The most effective photosensitizers in V-PDT (DLI = 15 $\mathrm{min}$ ) have hydrophilic or amphiphilic character, i.e. sulfonic and selected sulfonamide derivatives of bacteriochlorins (F2BOH, $\log \mathrm{P}=-1.4 ; \mathrm{F} 2 \mathrm{BMet} \log \mathrm{P}=1.9)$. The PDT protocol optimized for these photosensitizers led to $>80 \%$ cure rates. More lipophilic photosensitizers (Cl2BHep, $\log \mathrm{P} \approx 4.5$ ) proved to be more effective in protocols characterized by a longer DLI of $72 \mathrm{~h}$. Such compounds, due to their limited solubility in the aqueous medium, need specialized formulations, such as encapsulation in Pluronic poloxamers micelles. This may be an additional challenge, but it comes with the advantages of increased stability, selectivity and overall efficacy.

The different PDT regimes lead to different biological responses that can have distinct immunological components and contribute to the overall PDT efficacy. Various degree of local inflammation is observed after different PDT regimes. Multiplex analysis of selected cytokines present in the blood before and $24 \mathrm{~h}$ after the PDT showed increased IL- 6 concentrations in plasma after PDT, as expected from the inflammations observed. The enhanced concentration of KC and MIP- 2 chemokines after PDT suggest that tumor response may involve an influx of neutrophils to the tumor. The optimal protocols with sulfonamide bacteriochlorin (F2BMet-V-PDT and Cl2BHep-C-PDT) are characterized by increased secretion of MIP-1, which is also involved in neutrophilic inflammation.

The selected optimal protocols indicate the increased level of TNF $\alpha$ activity and decreased VEGF, especially after anti-vascular treatment. Further studies are necessary to fully understand how the 
changes in these biomarkers after PDT contribute to mounting an adaptive immune response capable of inducing immunological memory and recognition of tumor cells surviving the local PDT treatment.

Author Contributions: Conceptualization, J.M.D. and L.G.A; methodology, J.M.D. and L.G.A.; validation, J.M.D. and L.G.A.; formal analysis, B.P. and J.M.D.; investigation, B.P., L.G.A. and J.M.D.; resources, J.M.D. and L.G.A.; data curation, B.P. and J.M.D.; writing—original draft preparation, B.P. and J.M.D.; writing—review and editing, J.M.D. and L.G.A.; visualization, B.P.; supervision, J.M.D.; project administration, J.M.D.; funding acquisition, L.G.A. and J.M.D. All authors have read and agreed to the published version of the manuscript.

Funding: This research was funded by National Science Center (NCN), Poland, Sonata Bis grant number 2016/22/E/NZ7/00420 given to J.M.D. BP thanks Foundation for Polish Science for START 071.2019 program. L.G.A. thanks Portuguese Science Foundation (FCT, Portugal) for projects PTDC/QEQ-MED/3521/2014 and Pest-OE/QUI/UI0313/2014.

Acknowledgments: The authors thank Luzitin S.A. for providing redaporfin and Mariette M. Pereira, the leader of Catalysis and Fine Chemistry group at Coimbra Chemistry Center (CQC) for the synthesis of $\mathrm{F}_{2} \mathrm{BOH}$ and $\mathrm{Cl}_{2} \mathrm{BHep}$.

Conflicts of Interest: The authors declare no conflict of interest.

\section{References}

1. Kessel, D. Photodynamic Therapy: A Brief History. J. Clin. Med. 2019, 8, 1581. [CrossRef]

2. Dabrowski, J.M.; Arnaut, L.G. Photodynamic therapy (PDT) of cancer: From local to systemic treatment. Photochem. Photobiol. Sci. 2015, 14, 1765-1780. [CrossRef]

3. Dabrowski, J.M. Reactive oxygen species in photodynamic therapy: Mechanisms of their generation and potentiation. In Advances in Inorganic Chemistry; Elsevier: Amsterdam, The Netherlands, 2017; Volume 70, pp. 343-394.

4. $\quad$ Agostinis, P.; Berg, K.; Cengel, K.A.; Foster, T.H.; Girotti, A.W.; Gollnick, S.O.; Hahn, S.M.; Hamblin, M.R.; Juzeniene, A.; Kessel, D.; et al. Photodynamic therapy of cancer: An update. CA Cancer J. Clin. 2011, 61, 250-281. [CrossRef]

5. Krzykawska-Serda, M.; Dabrowski, J.M.; Arnaut, L.G.; Szczygieł, M.; Urbańska, K.; Stochel, G.; Elas, M. The role of strong hypoxia in tumors after treatment in the outcome of bacteriochlorin-based photodynamic therapy. Free Radic. Biol. Med. 2014, 73, 239-251. [CrossRef]

6. Karwicka, M.; Pucelik, B.; Gonet, M.; Elas, M.; Dabrowski, J.M. Effects of Photodynamic Therapy with Redaporfin on Tumor Oxygenation and Blood Flow in a Lung Cancer Mouse Model. Sci. Rep. 2019, 9, 1-15. [CrossRef]

7. Donohoe, C.; Senge, M.O.; Arnaut, L.G.; Gomes-da-Silva, L.C. Cell death in photodynamic therapy: From oxidative stress to anti-tumor immunity. Biochim. Biophys. Acta Rev. Cancer 2019, 1872, 188308. [CrossRef]

8. Chen, B.; Pogue, B.W.; Hoopes, P.J.; Hasan, T. Vascular and cellular targeting for photodynamic therapy. Crit. Rev. Eukaryot. Gene Expr. 2006, 16. [CrossRef]

9. García-Díaz, M.; Kawakubo, M.; Mroz, P.; Sagristà, M.L.; Mora, M.; Nonell, S.; Hamblin, M.R. Cellular and vascular effects of the photodynamic agent temocene are modulated by the delivery vehicle. J. Control. Release 2012, 162, 355-363. [CrossRef]

10. Kiesslich, T.; Krammer, B.; Plaetzer, K. Cellular mechanisms and prospective applications of hypericin in photodynamic therapy. Curr. Med. Chem. 2006, 13, 2189-2204. [CrossRef]

11. Krammer, B. Vascular effects of photodynamic therapy. Anticancer Res. 2001, 21, 4271-4277.

12. Pucelik, B.; Arnaut, L.G.; Stochel, G.Y.; Dabrowski, J.M. Design of Pluronic-based formulation for enhanced redaporfin-photodynamic therapy against pigmented melanoma. ACS Appl. Mater. Interfaces 2016, 8, 22039-22055. [CrossRef]

13. Dabrowski, J.M.; Pucelik, B.; Regiel-Futyra, A.; Brindell, M.; Mazuryk, O.; Kyzioł, A.; Stochel, G.; Macyk, W.; Arnaut, L.G. Engineering of relevant photodynamic processes through structural modifications of metallotetrapyrrolic photosensitizers. Coord. Chem. Rev. 2016, 325, 67-101. [CrossRef]

14. Castano, A.P.; Demidova, T.N.; Hamblin, M.R. Mechanisms in photodynamic therapy: Part one-photosensitizers, photochemistry and cellular localization. Photodiagnosis Photodyn. Ther. 2004, 1, 279-293. [CrossRef] 
15. Saavedra, R.; Rocha, L.B.; Dabbrowski, J.M.; Arnaut, L.G. Modulation of biodistribution, pharmacokinetics, and photosensitivity with the delivery vehicle of a bacteriochlorin photosensitizer for photodynamic therapy. ChemMedChem 2014, 9, 390-398. [CrossRef]

16. Jori, G.; Reddi, E. The role of lipoproteins in the delivery of tumour-targeting photosensitizers. Int. J. Biochem. 1993, 25, 1369-1375. [CrossRef]

17. Huang, Y.-Y.; Mroz, P.; Zhiyentayev, T.; Sharma, S.K.; Balasubramanian, T.; Ruzié, C.; Krayer, M.; Fan, D.; Borbas, K.E.; Yang, E.; et al. In vitro photodynamic therapy and quantitative structure-Activity relationship studies with stable synthetic near-infrared-absorbing bacteriochlorin photosensitizers. J. Med. Chem. 2010, 53, 4018-4027. [CrossRef]

18. Oliveira, C.S.; Turchiello, R.; Kowaltowski, A.J.; Indig, G.L.; Baptista, M.S. Major determinants of photoinduced cell death: Subcellular localization versus photosensitization efficiency. Free Radic. Biol. Med. 2011, 51, 824-833. [CrossRef]

19. Brandis, A.; Mazor, O.; Neumark, E.; Rosenbach-Belkin, V.; Salomon, Y.; Scherz, A. Novel Water-soluble Bacteriochlorophyll Derivatives for Vascular-targeted Photodynamic Therapy: Synthesis, Solubility, Phototoxicity and the Effect of Serum Proteins. Photochem. Photobiol. 2005, 81, 983-992. [CrossRef]

20. Azzouzi, A.R.; Barret, E.; Moore, C.M.; Villers, A.; Allen, C.; Scherz, A.; Muir, G.; de Wildt, M.; Barber, N.J.; Lebdai, S.; et al. TOOKADßS oluble vascular-targeted photodynamic (VTP) therapy: Determination of optimal treatment conditions and assessment of effects in patients with localised prostate cancer. BJU Int. 2013, 112, 766-774. [CrossRef]

21. Rocha, L.B.; Gomes-da-Silva, L.C.; Dąbrowski, J.M.; Arnaut, L.G. Elimination of primary tumours and control of metastasis with rationally designed bacteriochlorin photodynamic therapy regimens. Eur. J. Cancer 2015, 51, 1822-1830. [CrossRef]

22. Rocha, L.; Schaberle, F.; Dąbrowski, J.; Simões, S.; Arnaut, L. Intravenous single-dose toxicity of redaporfin-based photodynamic therapy in rodents. Int. J. Mol. Sci. 2015, 16, 29236-29249. [CrossRef]

23. Arnaut, L.G.; Pereira, M.M.; Dabrowski, J.M.; Silva, E.F.; Schaberle, F.A.; Abreu, A.R.; Rocha, L.B.; Barsan, M.M.; Urbańska, K.; Stochel, G.; et al. Photodynamic therapy efficacy enhanced by dynamics: The role of charge transfer and photostability in the selection of photosensitizers. Chem. A Eur. J. 2014, 20, 5346-5357. [CrossRef]

24. Luz, A.F.; Pucelik, B.; Pereira, M.M.; Dabbrowski, J.M.; Arnaut, L.G. Translating phototherapeutic indices from in vitro to in vivo photodynamic therapy with bacteriochlorins. Lasers Surg. Med. 2018, 50, 451-459. [CrossRef]

25. Dąbrowski, J.M.; Arnaut, L.G.; Pereira, M.M.; Urbańska, K.; Simões, S.; Stochel, G.; Cortes, L. Combined effects of singlet oxygen and hydroxyl radical in photodynamic therapy with photostable bacteriochlorins: Evidence from intracellular fluorescence and increased photodynamic efficacy in vitro. Free Radic. Biol. Med. 2012, 52, 1188-1200. [CrossRef]

26. Dąbrowski, J.M.; Urbanska, K.; Arnaut, L.G.; Pereira, M.M.; Abreu, A.R.; Simões, S.; Stochel, G. Biodistribution and photodynamic efficacy of a water-soluble, stable, halogenated bacteriochlorin against melanoma. ChemMedChem 2011, 6, 465-475. [CrossRef]

27. Pereira, M.M.; Monteiro, C.J.; Simões, A.V.; Pinto, S.M.; Arnaut, L.G.; Sá, G.F.; Silva, E.F.; Rocha, L.B.; Simões, S.; Formosinho, S.J. Synthesis and photophysical properties of amphiphilic halogenated bacteriochlorins: New opportunities for photodynamic therapy of cancer. J. Porphyr. Phthalocyanines 2009, 13, 567-573. [CrossRef]

28. Dąbrowski, J.M.; Arnaut, L.G.; Pereira, M.M.; Urbańska, K.; Stochel, G. Improved biodistribution, pharmacokinetics and photodynamic efficacy using a new photostable sulfonamide bacteriochlorin. MedChemComm 2012, 3, 502-505. [CrossRef]

29. Pandey, R.K.; Potter, W.R.; Dougherty, T.J. Fluorinated Photosensitizers Related to Chlorins and Bacteriochlorins for Photodynamic Therapy. U.S. Patent 7,166,719, 23 January 2007.

30. Pandey, S.K.; Gryshuk, A.L.; Graham, A.; Ohkubo, K.; Fukuzumi, S.; Dobhal, M.P.; Zheng, G.; Ou, Z.; Zhan, R.; Kadish, K.M.; et al. Fluorinated photosensitizers: Synthesis, photophysical, electrochemical, intracellular localization, in vitro photosensitizing efficacy and determination of tumor-uptake by $19 \mathrm{~F}$ in vivo NMR spectroscopy. Tetrahedron 2003, 59, 10059-10073. [CrossRef]

31. Goslinski, T.; Piskorz, J. Fluorinated porphyrinoids and their biomedical applications. J. Photochem. Photobiol. C Photochem. Rev. 2011, 12, 304-321. [CrossRef] 
32. Gryshuk, A.L.; Graham, A.; Pandey, S.K.; Potter, W.R.; Missert, J.R.; Oseroff, A.; Dougherty, T.J.; Pandey, R.K. A First Comparative Study of Purpurinimide-based Fluorinated vs. Nonfluorinated Photosensitizers for Photodynamic Therapy. Photochem. Photobiol. 2002, 76, 555-559. [CrossRef]

33. Naumann, K. Influence of chlorine substituents on biological activity of chemicals. J. Prakt. Chem. 1999, 341, 417-435. [CrossRef]

34. Naumann, K. Influence of chlorine substituents on biological activity of chemicals: A review. Pest Manag. Sci. Former. Pestic. Sci. 2000, 56, 3-21. [CrossRef]

35. Castano, A.P.; Mroz, P.; Hamblin, M.R. Photodynamic therapy and anti-tumour immunity. Nat. Rev. Cancer 2006, 6, 535. [CrossRef]

36. Korbelik, M.; Dougherty, G.J. Photodynamic therapy-mediated immune response against subcutaneous mouse tumors. Cancer Res. 1999, 59, 1941-1946.

37. Gollnick, S.O.; Brackett, C.M. Enhancement of anti-tumor immunity by photodynamic therapy. Immunol. Res. 2010, 46, 216-226. [CrossRef]

38. Wyld, L.; Reed, M.; Brown, N. Differential cell death response to photodynamic therapy is dependent on dose and cell type. Br. J. Cancer 2001, 84, 1384. [CrossRef]

39. Nowis, D.; Stokłosa, T.; Legat, M.; Issat, T.; Jakóbisiak, M.; Gołąb, J. The influence of photodynamic therapy on the immune response. Photodiagnosis Photodyn. Ther. 2005, 2, 283-298. [CrossRef]

40. Garg, A.D.; Nowis, D.; Golab, J.; Agostinis, P. Photodynamic therapy: Illuminating the road from cell death towards anti-tumour immunity. Apoptosis 2010, 15, 1050-1071. [CrossRef]

41. Gomes-da-Silva, L.C.; Zhao, L.; Bezu, L.; Zhou, H.; Sauvat, A.; Liu, P.; Durand, S.; Leduc, M.; Souquere, S.; Loos, F; et al. Photodynamic therapy with redaporfin targets the endoplasmic reticulum and Golgi apparatus. EMBO J. 2018, 37. [CrossRef]

42. Brackett, C.M.; Gollnick, S.O. Photodynamic therapy enhancement of anti-tumor immunity. Photochem. Photobiol. Sci. 2011, 10, 649-652. [CrossRef]

43. Korbelik, M.; Naraparaju, V.; Yamamoto, N. Macrophage-directed immunotherapy as adjuvant to photodynamic therapy of cancer. Br. J. Cancer 1997, 75, 202. [CrossRef] [PubMed]

44. Sun, J.; Cecic, I.; Parkins, C.S.; Korbelik, M. Neutrophils as inflammatory and immune effectors in photodynamic therapy-treated mouse SCCVII tumours. Photochem. Photobiol. Sci. 2002, 1, 690-695. [CrossRef] [PubMed]

45. Garg, A.D.; Dudek, A.M.; Agostinis, P. Cancer immunogenicity, danger signals, and DAMPs: What, when, and how? Biofactors 2013, 39, 355-367. [CrossRef] [PubMed]

46. Garg, A.D.; Krysko, D.V.; Vandenabeele, P.; Agostinis, P. DAMPs and PDT-mediated photo-oxidative stress: Exploring the unknown. Photochem. Photobiol. Sci. 2011, 10, 670-680. [CrossRef] [PubMed]

47. Krysko, D.V.; Garg, A.D.; Kaczmarek, A.; Krysko, O.; Agostinis, P.; Vandenabeele, P. Immunogenic cell death and DAMPs in cancer therapy. Nat. Rev. Cancer 2012, 12, 860-875. [CrossRef]

48. Pereira, M.M.; Monteiro, C.J.; Simões, A.V.; Pinto, S.M.; Abreu, A.R.; Sá, G.F.; Silva, E.F.; Rocha, L.B.; Dabrowski, J.M.; Formosinho, S.J.; et al. Synthesis and photophysical characterization of a library of photostable halogenated bacteriochlorins: An access to near infrared chemistry. Tetrahedron 2010, 66, 9545-9551. [CrossRef]

49. Silva, E.F.F.D. Transparent Photochemistry: Infrared Photosensitizers and Singlet Oxygen Microscopy; Universidade de Coimbra: Coimbra, Portugal, 2013.

50. Huang, Y.Y.; Balasubramanian, T.; Yang, E.; Luo, D.; Diers, J.R.; Bocian, D.F.; Lindsey, J.S.; Holten, D.; Hamblin, M.R. Stable synthetic bacteriochlorins for photodynamic therapy: Role of dicyano peripheral groups, central metal substitution (2H, Zn, Pd), and Cremophor EL delivery. ChemMedChem 2012, 7, 2155-2167. [CrossRef]

51. Vakrat-Haglili, Y.; Weiner, L.; Brumfeld, V.; Brandis, A.; Salomon, Y.; Mcllroy, B.; Wilson, B.C.; Pawlak, A.; Rozanowska, M.; Sarna, T.; et al. The microenvironment effect on the generation of reactive oxygen species by Pd- bacteriopheophorbide. J. Am. Chem. Soc. 2005, 127, 6487-6497. [CrossRef]

52. Ashur, I.; Goldschmidt, R.; Pinkas, I.; Salomon, Y.; Szewczyk, G.; Sarna, T.; Scherz, A. Photocatalytic Generation of Oxygen Radicals by the Water-Soluble Bacteriochlorophyll Derivative WST11, Noncovalently Bound to Serum Albumin. J. Phys. Chem. A 2009, 113, 8027-8037. [CrossRef] 
53. Madar-Balakirski, N.; Tempel-Brami, C.; Kalchenko, V.; Brenner, O.; Varon, D.; Scherz, A.; Salomon, Y. Permanent occlusion of feeding arteries and draining veins in solid mouse tumors by vascular targeted photodynamic therapy (VTP) with Tookad. PLoS ONE 2010, 5, e10282. [CrossRef]

54. Pucelik, B.; Paczyński, R.; Dubin, G.; Pereira, M.M.; Arnaut, L.G.; Dąbrowski, J.M. Properties of halogenated and sulfonated porphyrins relevant for the selection of photosensitizers in anticancer and antimicrobial therapies. PLoS ONE 2017, 12, e0185984. [CrossRef] [PubMed]

55. Moan, J.; Berg, K.; Kvam, E.; Western, A.; Malik, Z.; Rück, A.; Schneckenburger, H. Intracellular localization of photosensitizers. In Ciba Foundation Symposium 146-Photosensitizing Compounds: Their Chemistry, Biology and Clinical Use: Photosensitizing Compounds: Their Chemistry, Biology and Clinical Use: Ciba Foundation Symposium 146; Wiley Online Library: Hoboken, NJ, USA, 2007; pp. 95-111.

56. Kessel, D.; Luo, Y. Intracellular sites of photodamage as a factor in apoptotic cell death. J. Porphyr. Phthalocyanines 2001, 5, 181-184. [CrossRef]

57. Sobczynski, J.; Kristensen, S.; Berg, K. The influence of Pluronics nanovehicles on dark cytotoxicity, photocytotoxicity and localization of four model photosensitizers in cancer cells. Photochem. Photobiol. Sci. 2014, 13, 8-22. [CrossRef] [PubMed]

58. Mazor, O.; Brandis, A.; Plaks, V.; Neumark, E.; Rosenbach-Belkin, V.; Salomon, Y.; Scherz, A. WST11, A Novel Water-soluble Bacteriochlorophyll Derivative; Cellular Uptake, Pharmacokinetics, Biodistribution and Vascular-targeted Photodynamic Activity Using Melanoma Tumors as a Model. Photochem. Photobiol. 2005, 81, 342-351. [CrossRef] [PubMed]

59. Hajri, A.; Wack, S.; Meyer, C.; Smith, M.; Leberquier, C.; Kedinger, M.; Aprahamian, M. In Vitro and In Vivo Efficacy of Photofrinßand Pheophorbide a, a Bacteriochlorin, in Photodynamic Therapy of Colonic Cancer Cells. Photochem. Photobiol. 2002, 75, 140-148. [CrossRef]

60. Li, L.-B.; Luo, R.-C. Effect of drug-light interval on the mode of action of Photofrin photodynamic therapy in a mouse tumor model. Lasers Med Sci. 2009, 24, 597-603. [CrossRef]

61. Gollnick, S.; Evans, S.; Baumann, H.; Owczarczak, B.; Maier, P.; Vaughan, L.; Wang, W.; Unger, E.; Henderson, B. Role of cytokines in photodynamic therapy-induced local and systemic inflammation. Br. J. Cancer 2003, 88, 1772. [CrossRef]

62. Evans, S.; Matthews, W.; Perry, R.; Fraker, D.; Norton, J.; Pass, H.I. Effect of photodynamic therapy on tumor necrosis factor production by murine macrophages. JNCI J. Natl. Cancer Inst. 1990, 82, 34-39. [CrossRef]

63. Gollnick, S.O.; Liu, X.; Owczarczak, B.; Musser, D.A.; Henderson, B.W. Altered expression of interleukin 6 and interleukin 10 as a result of photodynamic therapy in vivo. Cancer Res. 1997, 57, 3904-3909.

64. Liu, W.; Oseroff, A.R.; Baumann, H. Photodynamic therapy causes cross-linking of signal transducer and activator of transcription proteins and attenuation of interleukin- 6 cytokine responsiveness in epithelial cells. Cancer Res. 2004, 64, 6579-6587. [CrossRef]

65. Jakobisiak, M.; Golab, J.; Lasek, W. Interleukin 15 as a promising candidate for tumor immunotherapy. Cytokine Growth Factor Rev. 2011, 22, 99-108. [CrossRef]

66. Teague, R.M.; Sather, B.D.; Sacks, J.A.; Huang, M.Z.; Dossett, M.L.; Morimoto, J.; Tan, X.; Sutton, S.E.; Cooke, M.P.; Öhlén, C.; et al. Interleukin-15 rescues tolerant CD8+ T cells for use in adoptive immunotherapy of established tumors. Nat. Med. 2006, 12, 335. [CrossRef] [PubMed]

67. Sato, T.; Terai, M.; Tamura, Y.; Alexeev, V.; Mastrangelo, M.J.; Selvan, S.R. Interleukin 10 in the tumor microenvironment: A target for anticancer immunotherapy. Immunol. Res. 2011, 51, 170-182. [CrossRef] [PubMed]

68. Hoshino, Y.; Hatake, K.; Kasahara, T.; Takahashi, Y.; Ikeda, M.; Tomizuka, H.; Ohtsuki, T.; Uwai, M.; Mukaida, N.; Matsushima, K. Monocyte chemoattractant protein-1 stimulates tumor necrosis and recruitment of macrophages into tumors in tumor-bearing nude mice: Increased granulocyte and macrophage progenitors in murine bone marrow. Exp. Hematol. 1995, 23, 1035-1039. [PubMed]

69. De Filippo, K.; Dudeck, A.; Hasenberg, M.; Nye, E.; van Rooijen, N.; Hartmann, K.; Gunzer, M.; Roers, A.; Hogg, N. Mast cell and macrophage chemokines CXCL1/CXCL2 control the early stage of neutrophil recruitment during tissue inflammation. Blood 2013, 121, 4930-4937. [CrossRef]

70. Kousis, P.C.; Henderson, B.W.; Maier, P.G.; Gollnick, S.O. Photodynamic therapy enhancement of antitumor immunity is regulated by neutrophils. Cancer Res. 2007, 67, 10501-10510. [CrossRef] 
71. Tokunaga, R.; Zhang, W.; Naseem, M.; Puccini, A.; Berger, M.D.; Soni, S.; McSkane, M.; Baba, H.; Lenz, H.-J. CXCL9, CXCL10, CXCL11/CXCR3 axis for immune activation-a target for novel cancer therapy. Cancer Treat. Rev. 2018, 63, 40-47. [CrossRef]

72. Gorbachev, A.; Kish, D.; Fairchild, R. Induction of CXCL9/Mig expression in the tumor microenvironment promotes protective antitumor immune responses. Cancer Res. 2013, 73, 2231.

73. Kawczyk-Krupka, A.; Czuba, Z.; Szliszka, E.; Król, W.; Sieroń, A. The role of photosensitized macrophages in photodynamic therapy. Oncol. Rep. 2011, 26, 275-280. [CrossRef]

74. Solban, N.; Pål, S.K.; Alok, S.K.; Sung, C.K.; Hasan, T. Mechanistic investigation and implications of photodynamic therapy induction of vascular endothelial growth factor in prostate cancer. Cancer Res. 2006, 66, 5633-5640. [CrossRef]

(C) 2019 by the authors. Licensee MDPI, Basel, Switzerland. This article is an open access article distributed under the terms and conditions of the Creative Commons Attribution (CC BY) license (http://creativecommons.org/licenses/by/4.0/). 